\title{
Sensory Neuron Downregulation of the Kv9.1 Potassium Channel Subunit Mediates Neuropathic Pain following Nerve Injury
}

\author{
Christoforos Tsantoulas, ${ }^{1}$ Lan Zhu, ${ }^{1}$ Yasin Shaifta, ${ }^{2}$ John Grist, ${ }^{1}$ Jeremy P. T. Ward, ${ }^{2}$ Ramin Raouf, ${ }^{3}$ Gregory J. Michael, ${ }^{4}$ \\ and Stephen B. McMahon ${ }^{1}$ \\ ${ }^{1}$ Neurorestoration Group, Wolfson Centre for Age-Related Diseases, King's College London, SE1 1UL London, United Kingdom, ${ }^{2}$ Department of Asthma, \\ Allergy and Respiratory Science, School of Medicine, King's College London, SE1 9NH London, United Kingdom, ${ }^{3}$ Pfizer-KCL Pain Laboratories, Wolfson \\ Centre for Age-Related Diseases, King's College London, SE1 1UL London, United Kingdom, and ${ }^{4}$ Centre for Neuroscience and Trauma, Blizard Institute, \\ Bart's and The London School of Medicine and Dentistry, Queen Mary University of London, London E1 2AT, United Kingdom
}

Chronic neuropathic pain affects millions of individuals worldwide, is typically long-lasting, and remains poorly treated with existing therapies. Neuropathic pain arising from peripheral nerve lesions is known to be dependent on the emergence of spontaneous and evoked hyperexcitability in damaged nerves. Here, we report that the potassium channel subunit Kv9.1 is expressed in myelinated sensory neurons, but is absent from small unmyelinated neurons. Kv9.1 expression was strongly and rapidly downregulated following axotomy, with a time course that matches the development of spontaneous activity and pain hypersensitivity in animal models. Interestingly, siRNA-mediated knock-down of Kv9.1 in naive rats led to neuropathic pain behaviors. Diminished Kv9.1 function also augmented myelinated sensory neuron excitability, manifested as spontaneous firing, hyper-responsiveness to stimulation, and persistent afterdischarge. Intracellular recordings from ex vivo dorsal root ganglion preparations revealed that Kv9.1 knock-down was linked to lowered firing thresholds and increased firing rates under physiologically relevant conditions of extracellular potassium accumulation during prolonged activity. Similar neurophysiological changes were detected in animals subjected to traumatic nerve injury and provide an explanation for neuropathic pain symptoms, including poorly understood conditions such as hyperpathia and paresthesias. In summary, our results demonstrate that Kv9.1 dysfunction leads to spontaneous and evoked neuronal hyperexcitability in myelinated fibers, coupled with development of neuropathic pain behaviors.

\section{Introduction}

Injuries to peripheral nerves, either traumatic or disease associated, can lead to neuropathic pain that is persistent, severe, and refractory to treatment (O'Connor and Dworkin, 2009). Neuropathic pain sufferers most often complain of spontaneous pain, while many also report pain in response to non-noxious stimulation (allodynia) or disproportionate to the stimulus strength (hyperalgesia). Additionally, a percentage of patients experience sensory abnormalities (paresthesias), which may acquire an un-

\footnotetext{
Received July 25, 2012; revised 0ct. 3, 2012; accepted 0ct. 9, 2012.

Author contributions: C.T., R.R., G.J.M., and S.B.M. designed research; C.T., L.Z., Y.S., J.G., and G.J.M. performed research; Y.S. and J.P.T.W. contributed unpublished reagents/analytic tools; C.T. and L.Z. analyzed data; C.T. and S.B.M. wrote the paper.

This work was supported by the Wellcome Trust-funded London Pain Consortium (Grant 080504). L.Z. is funded by Engineering and Physical Sciences Research Council (Grant RG53462). Y.S. and J.P.T.W. are funded by the Wellcome Trust (Grant 087776). We thank D.L.H. Bennett, C. Farmer, and T. Sears for discussions and review of this manuscript.

The authors declare no competing financial interests.

Correspondence should be addressed to Stephen B. McMahon, Sherrington Professor of Physiology, Director, London Pain Consortium, King's College London, The Wolfson Wing, Hodgkin Building, Guy's Campus, SE1 1UL London, UK. E-mail: stephen.mcmahon@kcl.ac.uk.

C. Tsantoulas' present address: Pfizer-KCL Pain Laboratories, Wolfson Centre for Age-Related Diseases, King's College London, Guy's Campus, SE1 1UL London, UK.

DOI:10.1523/JNEUROSCI.3561-12.2012

Copyright $\odot 2012$ the authors $\quad 0270-6474 / 12 / 3217502-12 \$ 15.00 / 0$
}

pleasant quality (dysesthesias) (Haanpää et al., 2011). At present, neuropathic pain management is inadequate, with typically less than half of patients reporting satisfactory ( $50 \%$ or better) pain relief after treatment (O'Connor and Dworkin, 2009).

Several pathophysiological mechanisms have been identified that might contribute to pain states, but there is widespread agreement that a key driver is the emergence of spontaneous (ectopic) activity in damaged sensory neurons (Sheen and Chung, 1993; Yoon et al., 1996; Baron, 2009). The bulk of this activity develops within $24 \mathrm{~h}$ following peripheral nerve injury and is most prominently detected in myelinated A-fibers (Kajander and Bennett, 1992; Boucher et al., 2000; Michaelis et al., 2000). Interestingly, precluding transmission of these signals to the CNS via anesthetic block of myelinated afferents alleviates neuropathic pain symptoms in patients (Campbell et al., 1988; Gracely et al., 1992). Ectopic discharge can often be recorded from the neuroma site and axonal segments of damaged nerves, but the majority appears to originate in the soma of sensory neurons, which lie in the dorsal root ganglion (DRG) (Kajander and Bennett, 1992).

Among the plethora of DRG genes regulated by peripheral axotomy (LaCroix-Fralish et al., 2011), ion channels are attractive targets due to their prominent role in controlling neuronal excitability. Indeed, a substantial body of work has established 
important links between sodium channel function and altered excitability, particularly in acute and inflammatory pain states (Khasar et al., 1998; Abdulla and Smith, 2001; Amir et al., 2006; Cox et al., 2006). However, assessment of knock-out transgenics for the best sodium channel candidates reveals a persistence of neuropathic pain behavior and/or ectopic activity (Nassar et al., 2005, 2006). Moreover, due to a focus on nociceptor-specific pathways, the molecular determinants of ectopic excitability in myelinated DRG neurons remain unknown.

Given the fundamental role of voltage-gated potassium $(\mathrm{Kv})$ channels in limiting neuronal excitability, we speculated that loss of function of a Kv subunit could account for the excitability changes seen in pain states. Supporting this hypothesis, it has long been known that Kv blockers applied to sensory neurons increase the frequency of spontaneous discharge or initiate activity from silent fibers (Kajander and Bennett, 1992). However, the largely overlapping pharmacology of different $\mathrm{Kv}$ subunits has made it challenging to link the altered excitability to specific Kv members. Here, we have examined Kv9.1 (kcns1), a potassium channel subunit we previously found to be strongly regulated by traumatic injury (Maratou et al., 2009). We report that Kv9.1 is selectively expressed in large sensory neurons, and that its downregulation by axotomy is critically involved in myelinated fiber hyperexcitability and emergence of pain phenotypes.

\section{Materials and Methods}

Animals and experimental neuropathy. In all experiments, adult male Wistar rats $(150-250 \mathrm{~g})$ were used in accordance to UK Home Office regulations and institutional guidelines. Experimental neuropathy was induced by an L 5 spinal nerve transection (SNT; $n=20$ ) (Bennett et al., 2003). Briefly, rats were anesthetized via intraperitoneal injection of 0.25 $\mathrm{mg} \mathrm{kg}{ }^{-1}$ medetomidine/ $60 \mathrm{mg} \mathrm{kg}^{-1}$ ketamine solution, following which the vertebral transverse processes were exposed via a small skin incision and retraction of the paravertebral musculature. The L6 transverse process was partially removed and the L5 spinal nerve was identified, tightly ligated, and sectioned 1-2 $\mathrm{mm}$ distal to the silk ligature. Sham surgery $(n=4)$ was performed by exposing the L5 spinal nerve but without deliberately damaging it.

In situ hybridization and fluorescent immunohistochemistry. In situ hybridization (ISH) was performed on $4 \%$ paraformaldehyde (PFA)-fixed, 8 - $\mu$ m-thick DRG sections using ${ }^{35} \mathrm{~S}$ end-labeled probes (PerkinElmer), as previously described (Michael et al., 1997; Fricker et al., 2009). Probe sequences were as follows: Kv9.1, gtcgatgaggttgagcggatggcagaagaagttg; Kv2.1, tggaactcctgggactctccacgaagaaaccaga; and Kv2.2, tgcttgggaactcgtg gggatagacctttggatg, complementary to bases 1030-1063, 1954-1987, and 2650-2683 of kcns1 (accession number NM_053954.1), kcnb1 (accession number NM_013186.1), and kcnb2 (accession number NM_054000.2) mRNAs, respectively. As a control, the hybridization reaction was competed by addition of a 100 -fold excess of unlabeled oligonucleotide. Lack of staining in this control indicates that the probe is directed to a target that can be saturated, and therefore labeling is likely to be specific. Further confidence in the specificity of Kv9.1 detection was drawn by observation of an identical distribution pattern using a second probe (ctatgttttgctcaggcgtatggctcccatgcag) targeted to a distinct Kv9.1 mRNA region.

Immunohistochemistry (IHC) was performed using mouse anti$\beta 3$ tub (Promega, 1:2000), mouse anti-Neurofilament 200 (NF200; Sigma, 1:500), rabbit anti-gene-related peptide (CGRP; Sigma, 1:2000), mouse anti-Kv2.1 (Neuromab, 1:1000), mouse anti-Kv2.2 (Neuromab, 1:1000), rabbit anti-Kv9.1 (Sigma, 1:500), and rabbit anti-ATF3 (Santa Cruz Biotechnology, 1:200). Secondary antibodies were donkey antimouse Alexa Fluor 488 and donkey anti-rabbit Alexa Fluor 546 (Invitrogen, both 1:1000). Isolectin B4 (IB4) binding was visualized using biotinconjugated IB4 (Sigma, 1:200) and AMCA avidin D (Vector Laboratories, 1:400). For Kv2.2 IHC, tissue was subjected to antigen retrieval ( $10 \mathrm{~mm}$ citric acid, $\mathrm{pH} 6.0$, at $80^{\circ} \mathrm{C}$ for $30 \mathrm{~min}$ ), and immuno- reactivity signal was enhanced using the tyramide amplification method. When combined with ISH, IHC was performed first, as described previously (Calvo et al., 2010).

For analysis, images were acquired on a fluorescence microscope equipped with a polarized light block for epifluorescence. Image analysis was conducted using ImageJ software by a single experimenter, blinded to the sample identities. To determine Kv9.1 positivity, we measured the mRNA (ISH silver grain density) or protein (fluorescence) signal for each cell and compared it with the mean background signal of the image. A threshold of signal greater than mean background plus two times its SD was set, and cells with a value higher than this threshold were classified as Kv9.1 positive.

Assessment of Kv9.1 distribution in naive L5 DRG was performed by measuring the diameter of Kv9.1-positive or -negative neurons with a clearly visible nucleus from 10 to 15 sections ( $>300$ cell profiles) per animal $(n=4)$. Following this, the percentage of $\mathrm{Kv} 9.1$ neuron positivity in each size group was determined for each animal. Finally, the mean percentage and SE across all animals was calculated. The same method was used to calculate the allocation of Kv9.1(+) neurons within different size subgroups. Kv9.1 colocalization with neuronal markers was determined by taking counts from at least 5-10 L5 DRG sections ( $>300$ cells) per animal $(n=4)$, after which percentages and SEs were calculated as before. For analysis of Kv9.1 coexpression with Kv2 members, the same field of view was identified on adjacent sections separated by $8 \mu \mathrm{m}$. Microscope photos were taken ( $6-8$ sections/animal, $n=3)$, individual neurons visible in all views were identified, and counts of colocalization were carried out. For analysis of Kv9.1 expression in DRG after peripheral axotomy, the intensity of ISH or IHC signal minus background was calculated in all medium-large neurons $(>30 \mu \mathrm{m})$ of at least six sections $(100-200$ cells) per animal $(n=3-4)$. Analysis of siRNA knockdown by IHC was performed using the same method ( $\operatorname{siRNA}, n=6$; scrambled, $n=3)$.

Cell culture. Adult DRG neuron cultures were prepared from male Wistar rats, as previously described (Wong et al., 2006), in chambered glass slides (Labtek). Cultures were either fixed with $4 \%$ PFA and processed for ISH and IHC or subjected to RNA isolation for quantitative reverse transcription ( $\mathrm{qRT}$ )-PCR, as described in the relevant section. For in vitro validation of siRNA, pulmonary artery smooth muscle cells (PASMC) were isolated and cultured as previously described (Knock et al., 2008b). For determination of Kv9.1 knock-down efficiency, PASMC $(0.5 \times 106$ cells/well $)$ were electroporated with 250 nм each Kv9.1 siRNA $(n=3)$ or control nontargeting siRNA (Dharmacon; $n=6$ ), according to published protocols (Knock et al., 2008a). All Kv9.1 siRNAs were designed using the Dharmacon algorithm; passenger strand sequences were siRNA\#1, cuuggaaucuguaggauca; siRNA\#2, gaaaggugguacaaguguu; and siRNA\#3, guaccagucucuauuagau. Kv9.1 expression was analyzed by qRT-PCR at $24 \mathrm{~h}$ after transfection, using the Kv9.1 and GAPDH primers described below.

In vivo RNA interference. Anesthetized rats were subjected to a thoracic laminectomy and a silastic tube was inserted subdurally to lie just rostral to L3 DRG and externalized to deliver bolus injections (one injection per day for 4 consecutive days). Animals were allowed to recover for $5 \mathrm{~d}$ before treatment commenced. On the day of injection, siRNA was mixed with i-Fect (Neuromics) to a final concentration of $0.2 \mu \mathrm{g} \mu \mathrm{l}^{-1}$, according to published protocols (Luo et al., 2005). For each treatment, 10-20 $\mu \mathrm{l}$ of Kv9.1 siRNA or scrambled control mixture was injected, followed by a $10 \mu \mathrm{l}$ saline flush. Twenty-four hours after the fourth injection animals were killed and L5 DRGs fresh dissected for qRT-PCR analysis. A separate set of animals were PFA perfused and DRGs retrieved for IHC. Passenger strand sequences for Kv9.1 and scrambled control siRNAs were cuuggaaucuguaggauca and gaggcctaatcgatatgtt, respectively (Dharmacon; "in vivo processing" option).

Behavioral assessment. Behavioral testing was conducted by a single experimenter blinded to the identity of treatment. Mechanical and heat pain thresholds were averaged from both paws, using the automatic von Frey and Hargreaves methods, respectively, as previously described (Marchand et al., 2009). Baseline values were taken $1 \mathrm{~d}$ before siRNA treatment and pain responses were assessed $24 \mathrm{~h}$ post each injection thereafter (Kv9.1, $n=7$; scrambled, $n=6$ ). 
A
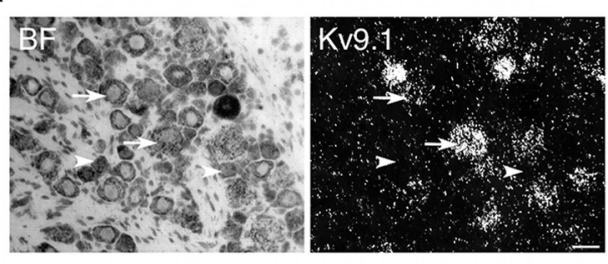

B

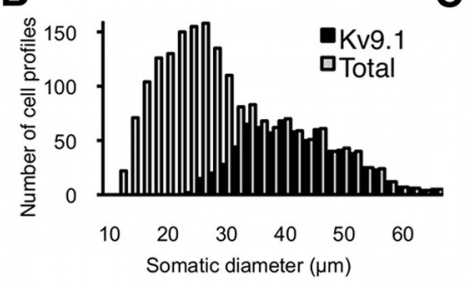

C

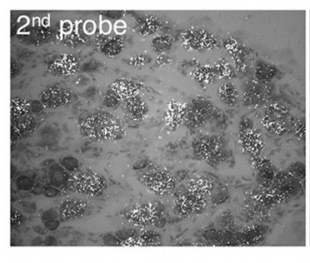

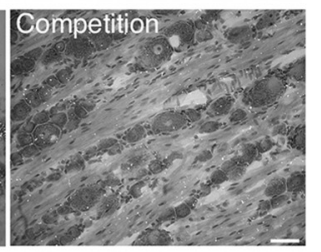

D

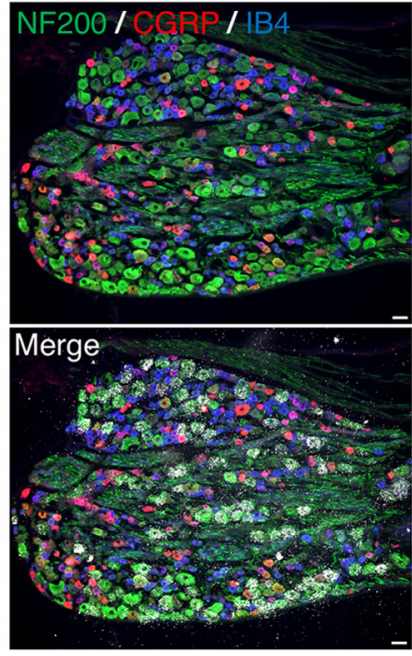

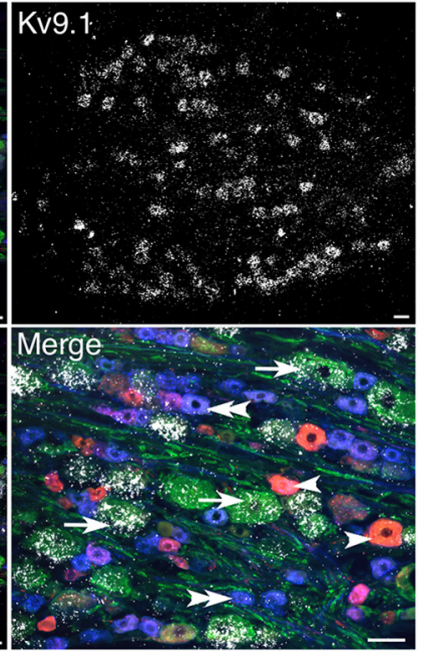

E

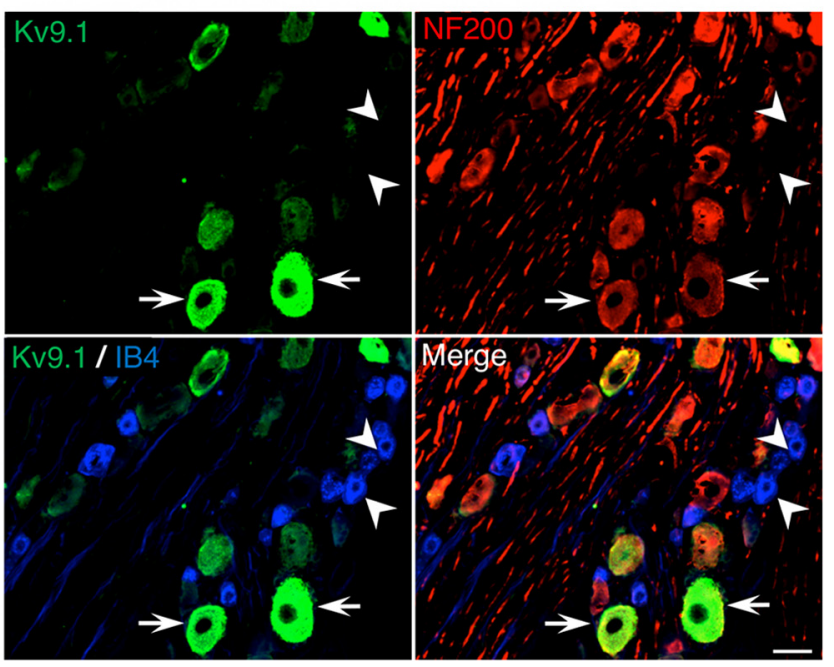

Figure 1. Kv9.1 is selectively expressed in myelinated sensory neurons. $A$, Bright-field (BF; left) and polarized light (right) images from Kv9.1 ISH in lumbar DRG showing mRNA silver grains over large (arrows), but not small (arrowheads) neurons. B, Kv9.1 cell-size distribution in rat lumbar DRG $(n=4)$. C, A similar expression pattern was detected using a different Kv9.1 mRNA probe (left), while control ISH reactions with excess unlabeled probe resulted in only background signal (right). $\boldsymbol{D}$, IHC for neuronal markers combined with Kv9.1 ISH in a single lumbar DRG section. Merged images (bottom, high power on right) illustrate Kv9.1 mRNA detection in NF200-positive neurons (arrows), while CGRP-positive (arrowheads) and IB4-positive (double arrowheads) neurons are devoid of Kv9.1 signal. $\boldsymbol{E}$, IHC showing Kv9.1 protein expression in large NF200(+), but not small (some distinguished by IB4 staining) neurons of lumbar DRG. Scale bar, $50 \mu \mathrm{m}$.

qRT-PCR. Twenty-four hours after the last injection, L5 DRG from both sides of control $(n=5)$ or Kv9.1 siRNA-treated animals $(n=7)$ were dissected and pooled. Total RNA was isolated using RNeasy Mini Kit (Qiagen) and cDNA was synthesized with Superscript II Reverse Transcriptase (Invitrogen), according to manufacturer's instructions. All samples were run in duplicates and GAPDH was used as an internal control. Primers used were Kv9.1; cggggaggagctcggagacc, acccacggccaggtacagca; GAPDH; ggctggggctcacctgaagg; and agcagttggtggtgcaggatgc. For amplification, $57.5 \mathrm{ng}$ cDNA was subjected to the following cycling conditions: (1) $95^{\circ} \mathrm{C}, 10 \mathrm{~min}$; (2) $95^{\circ} \mathrm{C}, 10 \mathrm{~s} ; 63^{\circ} \mathrm{C}, 10 \mathrm{~s} ; 72^{\circ} \mathrm{C}, 20 \mathrm{~s}(40$ cycles); and (3) temperature ramp to $95^{\circ} \mathrm{C}$. Amplification signal was detected using SYBR Green (Roche) on a Rotor-Gene 3000 (Corbett) and transcript levels were quantified using the $\Delta \Delta C_{\mathrm{t}}$ method.

In vivo electrophysiology. Recordings were performed on anesthetized rats ( $1.5 \mathrm{~g} \mathrm{~kg}^{-1}$ urethane, i.p.), $24 \mathrm{~h}$ after a $4 \mathrm{~d}$ treatment with $\mathrm{Kv} 9.1$ ( $n=$ $4)$ or scrambled control $(n=3)$ siRNA. Electrophysiological recordings from neuropathic animals were performed in rats with a partial sciatic nerve ligation (Bennett et al., 2003; $n=3$ ), 2-4 weeks postinjury. For each dataset, a fine L4/L5 dorsal root strand (10-15 strands per animal) was dissected from the dorsal root entry zone and mounted on the recording electrode, whereas the L4/L5 spinal nerve segment distal to the DRG was mounted on the stimulating electrode. All recordings commenced $5 \mathrm{~min}$ after acutely cutting the L4/L5 spinal nerve $\sim 10 \mathrm{~mm}$ distal to the DRG to remove most peripheral input. The number of units comprising each strand (typically $8-12$ ) was deciphered by evoking activity in the corresponding sensory axons via application of electrical stimulation at incremental intensities $(100 \mu$ s stimulus at $1 \mathrm{~Hz}$, up to $500 \mu \mathrm{A})$ on the spinal nerve. The activity on the root filament was filtered so that only A-fiber activity was registered. Dividing the conduction distance by the conduction time gave the conduction velocity of individual units. Following unit recruitment, each strand was monitored for spontaneously active units for $60 \mathrm{~s}$. After spontaneous activity (SA) assessment, the
Table 1. Quantitative measurements of Kv9.1 mRNA expression in rat lumbar DRG neurons of different sizes $(n=4)$

\begin{tabular}{lcl}
\hline & Percentage of DRG neurons \pm SE \\
\cline { 2 - 3 } & Kv9.1 $(+)$ cells in each class & $\begin{array}{l}\text { Allocation of Kv9.1 }(+) \\
\text { cells within different } \\
\text { classes }\end{array}$ \\
\hline Cell size (diameter) & $5.6 \pm 1.4 \%$ & $8.9 \pm 1.3 \%$ \\
Mediul $(<30 \mu \mathrm{m})$ & $77.6 \pm 5.3 \%$ & $31.2 \pm 2.2 \%$ \\
Large $(>40 \mu \mathrm{m})$ & $97.7 \pm 1.1 \%$ & $59.9 \pm 2.3 \%$ \\
\hline
\end{tabular}

Table 2. Quantitative measurements of Kv9.1 mRNA colocalization with neuronal markers in rat lumbar DRG $(n=4)$

\begin{tabular}{lcl}
\hline & Percentage of DRG neurons \pm SE & \\
\cline { 2 - 3 } Marker & Kv9.1 (+) cells in each group & $\begin{array}{l}\text { Allocation of Kv9.1 }(+) \\
\text { cells within different } \\
\text { groups }\end{array}$ \\
\hline CGRP & $3.5 \pm 1.0 \%$ & $4.0 \pm 1.4 \%$ \\
IB4 & $0.8 \pm 0.8 \%$ & $0.5 \pm 0.4 \%$ \\
NF200 & $97.2 \pm 0.7 \%$ & $93.1 \pm 1.5 \%$ \\
\hline
\end{tabular}

spinal nerve was sequentially stimulated at $2,5,10$, and $20 \mathrm{~Hz}(500 \mu \mathrm{A}$ stimulus, $10 \mathrm{~s}$ for each frequency) and the evoked activity in the corresponding strand was recorded for subsequent analysis. Finally, afterdischarge poststimulation was monitored for up to $60 \mathrm{~s}$. Activity incidence was calculated by dividing the total number of units showing SA or stimulus-evoked activity (SEA) with the total units sampled in each group (control, $n=269$; siRNA, $n=369$; injured, $n=176$ ). For calculation of firing rate during stimulation, the total number of spikes/s during the first $2 \mathrm{~s}$ of stimulation was determined at each stimulation 
A

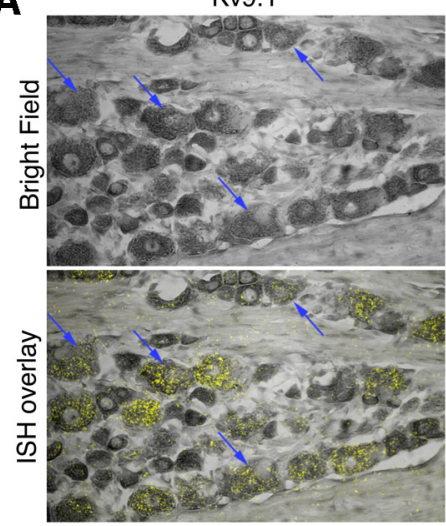

Kv2.1

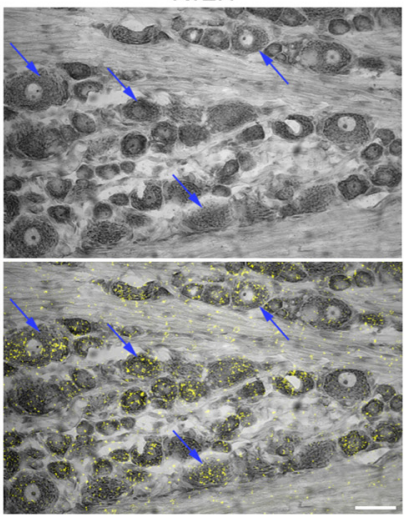

Kv9.1

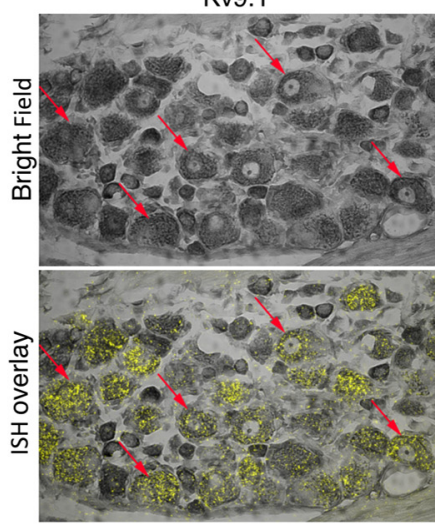

Kv2.2

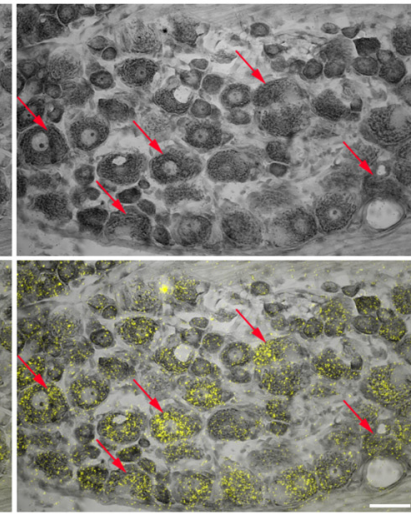

B

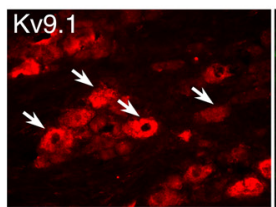

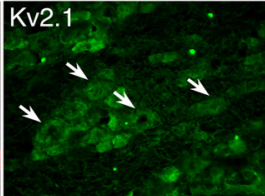

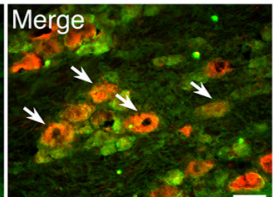

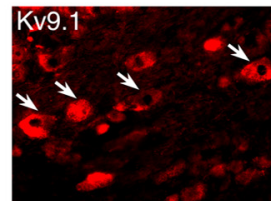
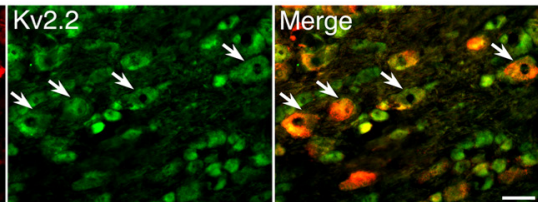

Figure 2. Kv9.1 is coexpressed with Kv2 subunits in myelinated sensory neurons. A, Bright-field (top) and ISH overlay (bottom) images for Kv9.1/Kv2.1 (left) and Kv9.1/Kv2.2 (right) colocalization detection on adjacent DRG sections. Arrows denote examples of the same neurons identified in both fields, expressing Kv9.1 and Kv2.1 (blue) or Kv9.1 and Kv2.2 (red) mRNAs. B, Immunohistological double labeling of DRG neurons for Kv9.1 and Kv2.1 (left) or Kv2.2 (right) proteins. Examples of colocalization in large neurons are denoted by arrows. Scale bars: $50 \mu \mathrm{m}$.

frequency for each group. The firing rate per unit was then calculated by dividing this value with the total number of active units in the group (control, $n=4$; siRNA, $n=22$; injured, $n=17$ ). After-discharge was expressed as the ratio of SEA spikes/s during the first $2 \mathrm{~s}$ poststimulation to total number of SEA units.

Ex vivo intracellular recordings. Four groups of animals were used: naive, injured (SNT), Kv9.1 siRNA-treated, and scrambled siRNA-treated. For injured animals, recordings were performed at 3-5 d after axotomy; for siRNA-treated animals, recordings were performed $24 \mathrm{~h}$ after the last of four successive injections, as before. On the day of recording, the animal was anesthetized with $25 \%$ urethane $(\mathrm{w} / \mathrm{v})\left(1.5 \mathrm{~g} \mathrm{~kg}^{-1}\right.$, i.p.), and L5/L4 DRG connected to the dorsal root and spinal nerve were dissected and transferred to a recovery chamber, filled with constantly oxygenated calcium-free Krebs' solution containing the following (in $\mathrm{mM}$ ): 124 $\mathrm{NaCl}, 26 \mathrm{NaHCO}_{3}, 1.3 \mathrm{NaH}_{2} \mathrm{PO}_{4}, 2 \mathrm{MgCl}_{2}, 2 \mathrm{CaCl}_{2}, 3 \mathrm{KCl}$, and 10 glucose. One hour later, the tissue was incubated for $20 \mathrm{~min}$ in $0.125 \%$ collagenase (Sigma) containing F12 medium (Invitrogen) at $37^{\circ} \mathrm{C}$, and then transferred to the recording chamber. The tissue was then constantly perfused with oxygenated $2 \mathrm{~mm} \mathrm{CaCl}_{2}$ containing Krebs' solution. When 6 and $9 \mathrm{~mm} \mathrm{KCl}$ was used in Krebs' solution, $\mathrm{NaCl}$ was adjusted accordingly to maintain the constant osmolarity (300 mOsm). The ganglion was pinned down with $U$-shaped pins on each side over dorsal root and spinal nerve and the end of the dorsal root was subjected to stimulation with a suction electrode. Sharp electrodes were pulled from borosilicate glass with filament $(\mathrm{OD} 1.5 \mathrm{~mm} \times$ ID $0.86 \mathrm{~mm}$; Sutter Instrument). Pipette resistance was 25-50 M $\Omega$ when filled with $3 \mathrm{~mm}$ KCl. Recordings were made with an Axoclamp 2B amplifier (Molecular Devices). Analog signals were lowpass filtered at $3 \mathrm{kHz}$ and sampled at 5 $\mathrm{kHz}$ using a Power 1401 computer interface. After successfully impaling a cell, the following protocol was applied: (1) obtain dorsal root stimulation-evoked action potential (AP) at $3 \mathrm{~mm}\left[\mathrm{~K}^{+}\right]_{\mathrm{e}}$; (2) at $3 \mathrm{~mm}$ $\left[\mathrm{K}^{+}\right]_{\mathrm{e}}$, a series of $100 \mathrm{~ms}$ current steps were injected into soma to obtain threshold current (minimum amount of current to evoke an AP), following which current was increased at $1 \mathrm{nA}$ increments up to 6-8 nA; (3) same procedure was repeated in 6 and $9 \mathrm{~mm}\left[\mathrm{~K}^{+}\right]_{\mathrm{e}}$. A small negative pulse $(-0.5 \mathrm{nA}, 20 \mathrm{~ms})$ was used to monitor input resistance. For the toxin experiment, we used the same protocol at $3 \mathrm{~mm}\left[\mathrm{~K}^{+}\right]_{\mathrm{e}}$ in the absence or presence of $100 \mathrm{~nm}$ stromatoxin-1 (Alomone Labs). Any recordings during which input resistance changed $>20 \%$ or resting membrane potential became more depolarized than $-45 \mathrm{mV}$ were discarded from analysis. Data were acquired and analyzed using Signal (CED).
Table 3. Quantitative measurements of Kv9.1 mRNA colocalization with Kv2 mRNA in rat lumbar DRG $(n=3)$

\begin{tabular}{lc}
\hline Subunit & Percentage of DRG neurons \pm SE \\
\hline Kv9.1 only & $11.25 \pm 0.4$ \\
Kv9.1 and Kv2.1 & $48.6 \pm 4.6$ \\
Kv9.1 and Kv2.2 & $76.8 \pm 7.0$ \\
Kv9.1 and Kv2.1 and Kv2.2 & $36.7 \pm 7.5$ \\
\hline
\end{tabular}

Values are reported as mean \pm SE. Unless otherwise stated, the two sample statistics were performed using Mann-Whitney $U$ test.

\section{Results}

Kv9.1 is selectively expressed in myelinated sensory neurons We first examined the expression of Kv9.1 transcripts in lumbar DRG sections of naive rats, using ISH. Kv9.1-positive staining was indicated by clusters of silver grains visible under polarized light over cells and was present in $39.8 \pm 3.0 \%$ of all neurons (Fig. $1 A)$. Size-frequency analysis revealed that Kv9.1 mRNA was robustly expressed in medium-large $(>30 \mu \mathrm{m}$ diameter, $89.7 \pm$ $1.5 \%)$, but not small ( $<30 \mu \mathrm{m}$ diameter, $5.6 \pm 1.4 \%)$ neurons (Fig. 1B; Table 1). Importantly, an identical distribution pattern was detected using a separate Kv9.1 probe (Fig. $1 C$, left; mediumlarge $88 \pm 3.3 \%$, small $4.5 \pm 1.8 \%$ ), while control reactions with an excess of unlabeled probe produced only background signal (Fig. $1 C$, right). In the total Kv9.1-positive population, most cells were medium-large diameter $(91.1 \pm 2.2 \%)$ and very few small diameter $(8.9 \pm 1.3 \%)$. To further characterize Kv9.1 expression in DRG we used three protein markers of neuronal subpopulations: NF200, which stains medium-large myelinated neurons; CGRP, present in small peptidergic nociceptors; and IB4, expressed in small nonpeptidergic nociceptors. Combined ISH and IHC for these markers in single sections (Fig. 1D; Table 2) showed colocalization of Kv9.1 with NF200, but not CGRP or IB4. Quantitatively, we observed that $93.1 \pm 1.5 \%$ of Kv9.1-positive cells were immunoreactive for NF200, while only $4.0 \pm 1.4 \%$ and $0.5 \pm 0.4 \%$ expressed the small cell markers CGRP and IB4, 
A
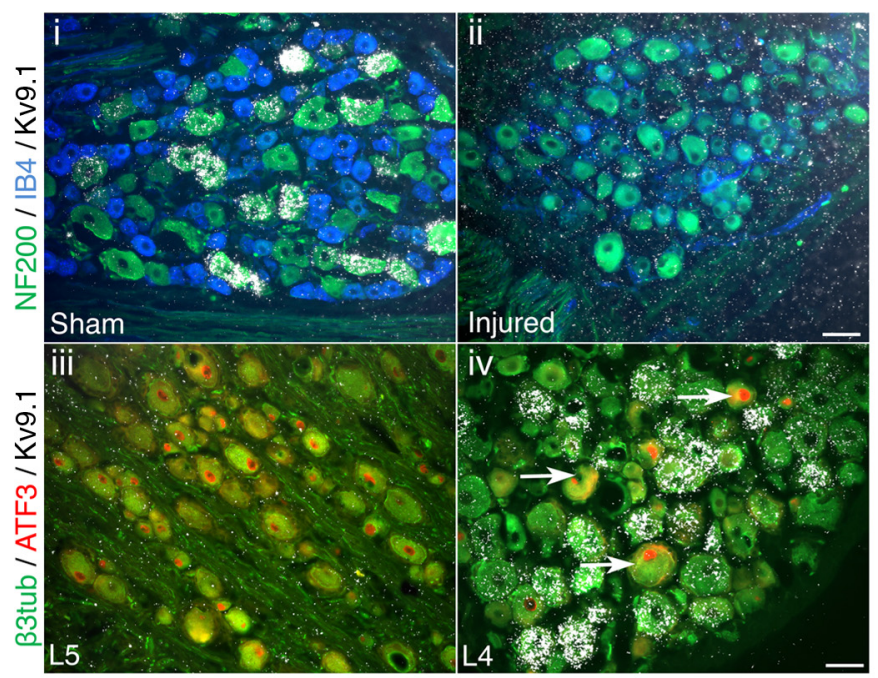

C

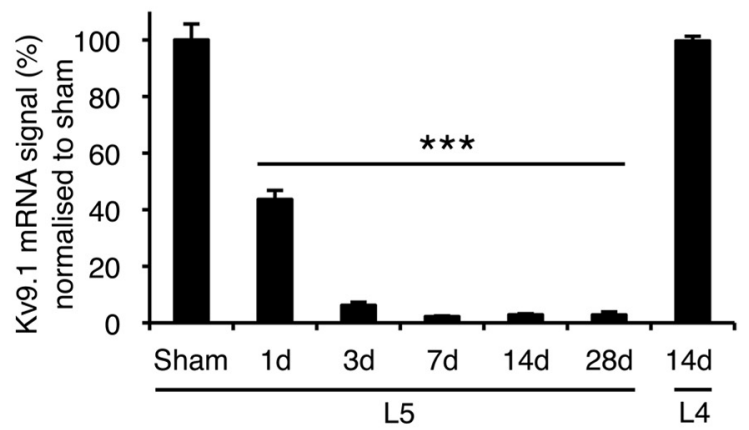

D

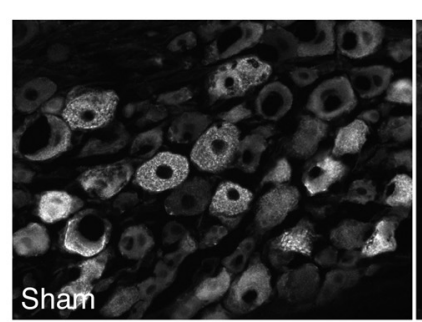

B

B
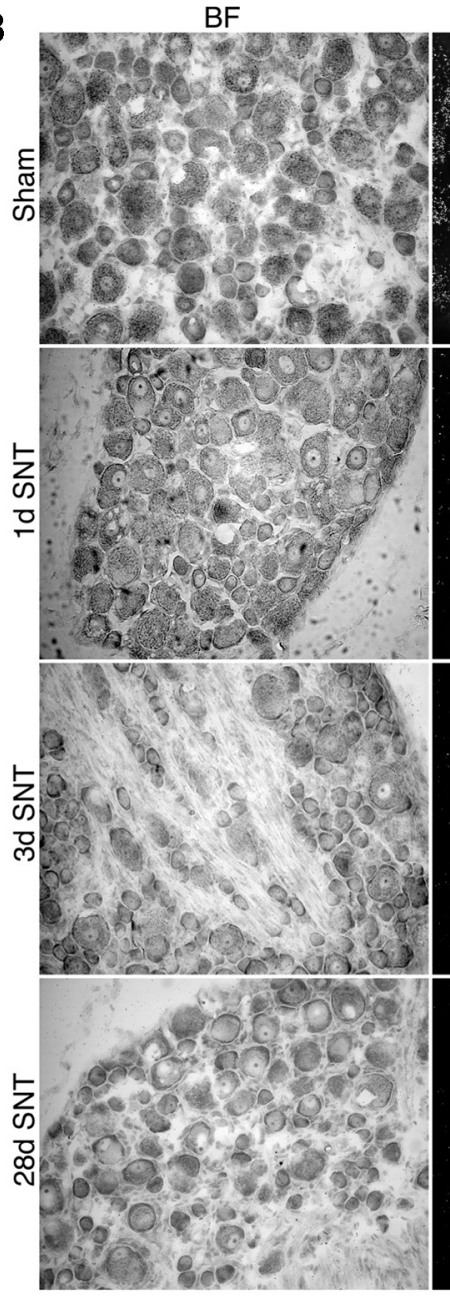

E

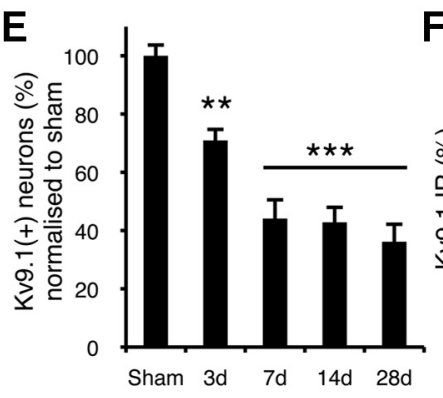

Kv9.1
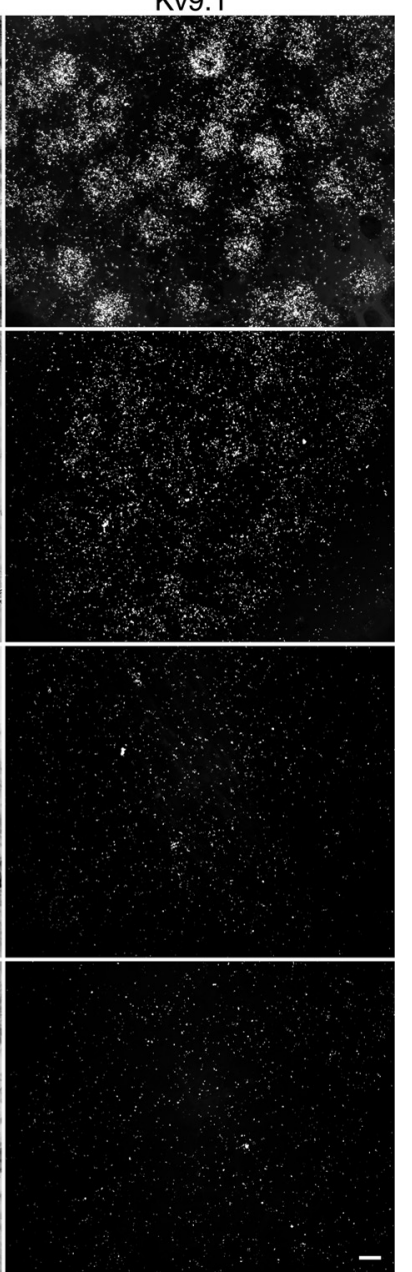

F

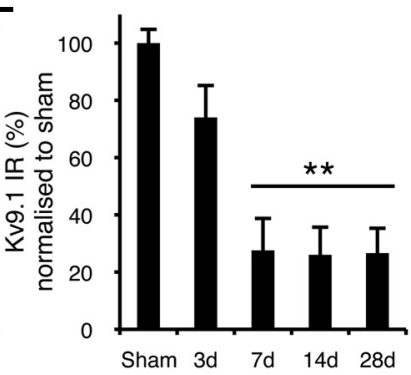

Figure 3. Kv9.1 is rapidly and robustly downregulated in DRG after nerve injury. $A$, Animals subjected to sham surgery retain Kv9.1 expression (i), while Kv9.1 mRNA signal is virtually absent in L5 DRG at 14 d postaxotomy (ii). All axotomized L5 DRG neurons lacking Kv9.1 signal are stained positive for the nerve injury marker ATF3 (iii). In the adjacent L 4 only a minority of neurons feature loss of Kv9.1 and these are also immunoreactive for ATF3 (arrows in iv). B, C, Images and quantification of Kv9.1 transcriptional downregulation after SNT, illustrating a rapid attenuation of mRNA levels in axotomized L5 DRG as soon as $1 \mathrm{~d}$ postinjury, with minimal expression detected as long as day 28 (mean \pm SEM; $n=4$ per time point; ${ }^{* * *} p<0.001$ vs sham, one-way ANOVA with Tukey's post hoc). D, Kv9.1 protein staining is reduced 7 d postinjury in lumbar DRG neurons. $\boldsymbol{E}, \boldsymbol{F}$, Quantification of Kv9.1 protein positivity and immunoreactivity (IR), respectively, showing Kv9.1 protein downregulation in medium-large neurons (mean $\pm \mathrm{SEM} ; n=3-4$ per time point; ${ }^{* *} p<0.01,{ }^{* * *} p<0.001$ vs sham, one-way ANOVA with Tukey's post hoc). Scale bars: $50 \mu \mathrm{m}$.

respectively. Conversely, most myelinated DRG cells, identified by NF200 staining, expressed Kv9.1 (97.2 $\pm 0.7 \%)$. In contrast, only $3.5 \pm 1.0 \%$ and $0.8 \pm 0.6 \%$ of CGRP or IB4-positive neurons, respectively, had Kv9.1 signal. Finally, to confirm our mRNA distribution results, we examined the protein expression using a commercial Kv9.1 antibody (Fig. 1E). In agreement with ISH results, Kv9.1 protein was detected in $82.7 \pm 2.5 \%$ of medium-large neurons, which also stained positive for NF200. Importantly, there were only background levels of fluorescence in smaller neurons, and no colocalization of Kv9.1 protein and IB4 staining was observed.
Kv9.1 colocalizes with Kv2 subunits in myelinated sensory neurons

Since previous studies have suggested that Kv9.1 function is linked to coassembly with Kv2.1 and Kv2.2 subunits (Salinas et al., 1997; Stocker and Kerschensteiner, 1998), we investigated whether Kv9.1 and Kv2 subunits are coexpressed in DRG neurons. To achieve this, we performed ISH (Fig. 2A) for Kv9.1/ Kv2.1 (left) and Kv9.1/Kv2.2 (right) in adjacent DRG sections and were able to directly observe colocalization of these mRNAs in single medium-large neurons (arrows). Examining the Kv9.1positive population, we found that 48.6 and $76.9 \%$ of cells coex- 
pressed Kv2.1 or Kv2.2, respectively (Table 3). The presence of both Kv2 subunits was documented in more than a third of all Kv9.1-positive neurons (36.7\%), while only a small number did not express any Kv2 subunit (11.25\%).

To extend the Kv9.1 and Kv2 coexpression data at the protein level, we performed double immunohistological labeling for Kv9.1 and either Kv2.1 (Fig. 2B, left) or Kv2.2 (Fig. 2B, right) using commercially available antibodies. This analysis confirmed the presence of Kv2 subunits in the majority of medium-large DRG neurons, where extensive colocalization with Kv9.1 protein was observed (arrows). In addition, both Kv2 subunits were also detected in many small neurons. Together, both ISH and IHC results demonstrate that Kv9.1 is highly colocalized with Kv2 members in myelinated neurons.

\section{Kv9.1 is rapidly and robustly downregulated after peripheral nerve injury}

To investigate Kv9.1 regulation after nerve injury we used L5 SNT in rats, a well characterized neuropathic pain model. Although Kv9.1 mRNA expression was normal in animals subjected to sham surgery, Kv9.1 mRNA signal was virtually absent in axotomized L5 DRG, $14 \mathrm{~d}$ postinjury (Fig. 3A, i,ii). Virtually all L5 neurons featuring Kv9.1 transcriptional downregulation were positive for the nerve injury marker activating transcription factor-3 (ATF3; Fig. 3A, iii). Examining the time course of Kv9.1 downregulation in more detail (Fig. $3 B$ ), we detected an $\sim 60 \%$ decrease (reduced to $43.6 \pm 3.2 \%$ of sham) in Kv9.1 levels as soon as $24 \mathrm{~h}$ postsurgery, and an almost complete loss of signal (reduced to $6.2 \pm 1.1 \%$ of sham) by $3 \mathrm{~d}(p<0.001)$, as quantified by ISH analysis (Fig. 3C). Kv9.1 downregulation was sustained, as mRNA transcripts remained at low levels for at least $28 \mathrm{~d}$. In the L4 DRG, Kv9.1 mRNA levels appeared unaltered in the majority of neurons ( $96.7 \pm 5.2 \%$ of sham, $p>0.1$; Fig. $3 C$ ), but in the few medium-large cells that expressed ATF3 (and were thus apparently injured by the surgical procedure) Kv9.1 signal was lost (Fig. $3 A$, iv). This observation is in agreement with reports that the nerve exposure involved in SNT can induce small but varying degrees of nerve injury in the spared L4 (Shortland et al., 2006).

Finally, we used IHC to confirm Kv9.1 downregulation at the protein level (Fig. 3D). As expected, the number of neurons positive for Kv9.1 protein was rapidly reduced after injury (3 d, $29.1 \pm 3.8 \%$ reduction compared with sham, $p<0.01)$ and remained low thereafter $(7 \mathrm{~d}, 55.9 \pm 6.4 \% ; 14 \mathrm{~d}, 57.2 \pm 5.1 \% ; 28 \mathrm{~d}$, $63.8 \pm 6.0 \%$ reductions vs sham, $p<0.001$; Fig. $3 E$ ). Similar conclusions were drawn from quantification of Kv9.1 immunoreactivity (at least 72\% reduction on days 7 through 28, $p<0.01$; Fig. $3 F$ ). In summary, the observed time course of Kv9.1 downregulation in injured neurons correlates with the emergence of A-fiber ectopic firing and pain behaviors in this model (Liu et al., 2000).

\section{Kv9.1 is also downregulated in dissociated DRG cultures}

To establish whether DRG cultures could constitute an in vitro system to investigate Kv9.1 function, we examined Kv9.1 expression in acutely dissociated DRG neurons. In this preparation, neurons undergo axotomy of their central and peripheral processes as part of the dissection process, and as a result feature many elements of injured phenotypes, such as ATF3 expression (Dussor et al., 2003). Cultures that were fixed after either 3 or $72 \mathrm{~h}$ postplating were stained for NF200 and CGRP and subjected to ISH. In line with our previous results, Kv9.1 could be detected in NF200-positive neurons at $3 \mathrm{~h}$; however, no mRNA was detected after $72 \mathrm{~h}$ (Fig. 4A). Subsequently, Kv9.1 expression was analyzed
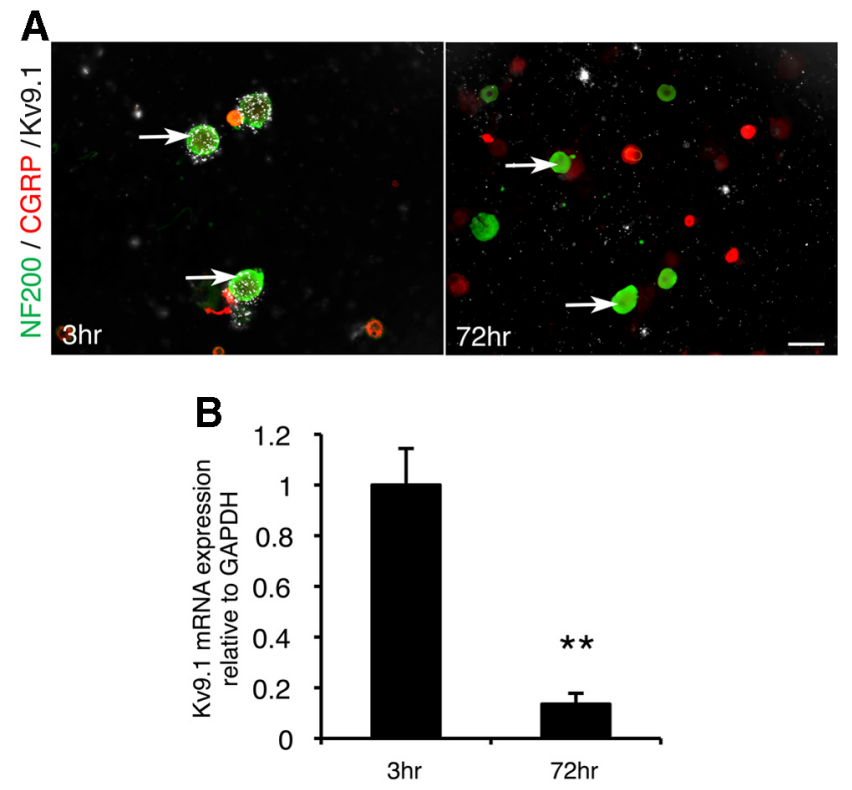

Figure 4. Kv9.1 is also downregulated in DRG culture. $\boldsymbol{A}$, Kv9.1 ISH combined with IHC for NF200 and CGRP in dissociated DRG culture demonstrates Kv9.1 mRNA reduction in large neurons (arrows) after $72 \mathrm{~h}$ in culture, compared with baseline ( $3 \mathrm{~h}$ postplating). $\boldsymbol{B}$, Quantification of Kv9.1 mRNA in vitro expression by qRT-PCR (mean $\pm S E M ; ~ n=3$ per dataset, ${ }^{* *} p<0.01, t$ test).

by qRT-PCR (Fig. $4 B$ ). The results indicated that after $72 \mathrm{~h}$ in culture, Kv9.1 signal is reduced by $86.5 \pm 4.3 \%$ ( $p<0.01)$ compared with baseline ( $3 \mathrm{~h}$ postplating), an effect comparable to SNT-induced in vivo downregulation.

\section{Kv9.1 knock-down elicits pain behaviors in naive animals}

We next sought to determine whether Kv9.1 downregulation precedes development of pain symptoms by experimentally inducing Kv9.1 knock-down in naive DRG via RNA interference. To achieve this, we initially tested three different siRNA oligonucleotide sequences for their ability to knock-down Kv9.1 in vitro. Since dissociated DRG neurons very rapidly lose Kv9.1 expression in culture, we assayed the siRNA sequences by electroporating rat PASMC, cells that have been reported to stably express Kv9.1 in culture (Fantozzi et al., 2006). Analysis of Kv9.1 expression by qRT-PCR $24 \mathrm{~h}$ post-transfection indicated that siRNA\#1 was the most effective, mediating a $85.2 \pm 1.3 \%$ mRNA knockdown $(p<0.01)$ compared with a control culture transfected with nontargeting siRNA (Fig. 5A). To examine the effect of Kv9.1 knock-down in vivo, siRNA\#1 was then delivered daily via indwelling intrathecal catheters to the lumbar space of adult rats for 4 consecutive days. At the end point of treatment, L5 DRGs were retrieved and qRT-PCR or IHC was used to quantify Kv9.1 expression levels. We observed a significant decrease in Kv9.1 mRNA levels in animals treated with the Kv9.1 siRNA (Fig. 5B), compared with a separate group of animals receiving vehicle or a scrambled sequence control with the same dosing regimen $(38.9 \pm 9.4 \%$ decrease vs scrambled, $p<0.05)$. Consistent with Kv9.1 mRNA knockdown, immunohistological examination of DRG sections using Kv9.1 antisera (Fig. 5C) also revealed a 23.9\% reduction in the percentage of Kv9.1-positive myelinated neurons (scrambled, $83.3 \pm 1.1$; siRNA, $63.4 \pm 3.8 \%, p<0.01$ ) as well as a $32.7 \%$ decrease in mean Kv9.1 signal intensity $(67.3 \pm$ $5.2 \%$ of scrambled control, $p<0.001$ ).

Intriguingly, behavioral assessment showed a significant reduction of mechanical pain thresholds in the animals treated with 
the Kv9.1 siRNA, compared with scrambled control (Fig. 5D). The mechanical hyperalgesia developed over several days and with this dose thresholds fell by $\sim 30 \%$ at $4 \mathrm{~d}$ post-treatment, which was significant compared with baseline or control group $(p<0.001)$. Interestingly, heat sensitivity of the hindpaws was not affected ( $p>0.1$; Fig. $5 E$ ).

\section{Kv9.1 knock-down triggers}

A-fiber hyperexcitability

We finally asked whether Kv9.1 siRNA treatment could replicate electrophysiological changes in sensory neurons that are known to occur in neuropathic states. In anesthetized rats, we recorded from centrally disconnected fine strands of the L4/L5 dorsal roots after $4 \mathrm{~d}$ of treatment with either Kv9.1 siRNA or scrambled control siRNA (Fig. 6A). Before recording, we acutely cut the L4 and L5 spinal nerves to remove peripheral input. We observed little SA in control animals (1.1\%), but a significantly higher number of strands sampled after Kv9.1 knockdown showed ectopic firing $(4.9 \%, p<$ 0.05 vs control; Fig. $6 B, D)$. The ectopic discharge, like that seen in neuropathic pain models, was observed in myelinated fibers (conduction velocity range 5-55 $\mathrm{m} / \mathrm{s}^{-1}$ ); was either tonic, irregular, or bursting; and had an average rate of $11.2 \pm 3.6 \mathrm{spikes} / \mathrm{s}^{-1}$. For comparison, using the same setup to record spontaneous firing in injured animals subjected to peripheral axotomy revealed a $7.4 \%$ SA incidence ( $p<0.01$ vs control).

When stimulating the spinal nerves of Kv9.1 siRNA-treated animals (Fig. 6A) at A-fiber strength, we observed a form of peripheral wind-up in many units $(6.1 \%, p<0.01$ vs control), including previously silent units without any apparent spontaneous firing. This excitability was manifested as a delayed and frequency-dependent activation of the unit, usually with a very prominent after-discharge, which we dubbed SEA (Fig. 6C, double arrowheads). In contrast, SEA was very rarely detected in scrambled siRNA-treated animals (1.5\%; Fig. 6C,D). Quantification of the firing rate (Fig. $6 E$ ) and after-discharge (Fig. $6 F$ ) of SEA units revealed statistically significant differences between Kv9.1 siRNA and control-treated groups $(p<0.05)$. Importantly, we confirmed that a very similar phenomenon could be observed in neuropathic animals subjected to nerve injury (Fig. $6 C-F)$ and this was again significant compared with control animals (incidence, $p<0.001$; firing rate, $p<0.05$ ). Interestingly, SEA was not exclusively linked to activation of the recorded axon, since increasing the stimulus strength to include C-fibers greatly augmented the degree of SEA seen in A-fibers, even at low stimulation frequencies (Fig. 7).

\section{Kv9.1 downregulation is linked to}

lower firing threshold at elevated extracellular potassium To gain additional mechanistic insight on the hyperexcitability changes after axotomy or experimental Kv9.1 knockdown, we All data represent mean \pm SEM.
B
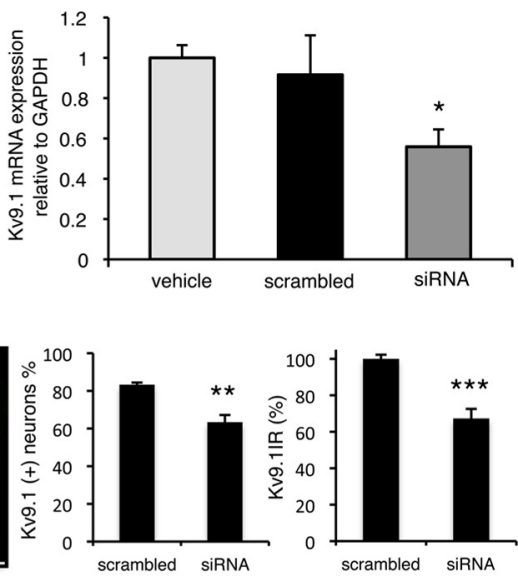

E

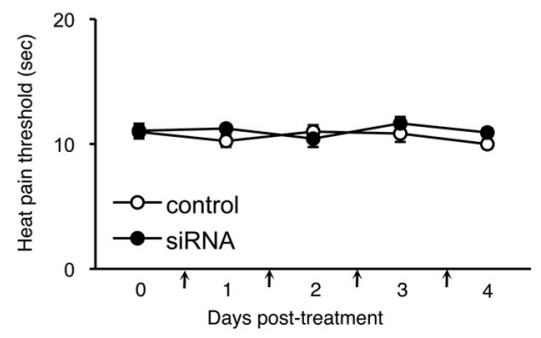

Figure 5. Intrathecal Kv9.1 siRNA treatment induces pain behaviors in naive rats. $A, q R T-P C R$ quantification of Kv9.1 mRNA in rat PASMC cultures transfected with one of three Kv9.1 siRNA sequences or control siRNA (control, $n=6$; siRNA, $n=3$ per group;

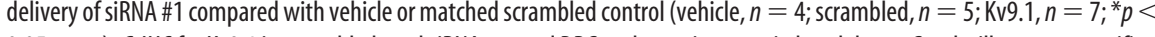
tion of number of positive myelinated neurons and mean Kv9.1 signal intensity (scrambled, $n=4$; siRNA, $n=6$; ** ${ }^{* * *} p<0.001, t$ test). D, Kv9.1 siRNA infusion inflicts a reduction in mechanical pain withdrawal thresholds (Kv9.1, $n=7$; control, $n=6$; ${ }^{*} p<0.05,{ }^{* *} p<0.01,{ }^{* * *} p<0.001$ vs scrambled control or baseline, two-way repeated measurements ANOVA with Tukey's). $\boldsymbol{E}$, There was no change in heat pain thresholds after siRNA treatment. Vertical arrows on $x$-axis denote siRNA injections.

performed ex vivo intracellular recordings from myelinated DRG neurons (conduction velocity range $3.5-30 \mathrm{~m} \mathrm{~s}^{-1}$ ) isolated from either naive, injured (3-5 d postaxotomy), or siRNA-treated animals (Table 4). Consistent with our previous results, some injured and Kv9.1 siRNA-treated neurons showed spontaneous firing (data not shown). This spontaneous firing was not seen in any of the naive or scrambled siRNA-treated cells. We then used dorsal root stimulation to study parameters of the evoked APs (Fig. $8 A$, left). In agreement with previous work (Ma et al., 2003; Sapunar et al., 2005), in injured neurons AP amplitude was smaller compared with naive neurons (71.09 \pm 3.04 vs $80.55 \pm 3.26 \mathrm{mV} ; p<0.05)$; AP half-width (APD50) was significantly widened $(1.59 \pm 0.21$ vs $0.87 \pm 0.11 \mathrm{~ms}, n=21 ; p<0.005)$; and maximum rising rate was slower (176.08 \pm 22.58 vs $243.78 \pm 21.65 \mathrm{mV} / \mathrm{ms}, p<0.05)$; afterhyperpolarization (AHP) amplitude was dramatically reduced (5.42 \pm 0.69 vs $13.08 \pm 0.82 \mathrm{mV}, p<0.001)$, despite no difference in AHP half-width (AHPD50) between groups (5.74 \pm 0.81 vs $5.39 \pm$ $1.28 \mathrm{mV}$ ). Comparison of AP parameters between scrambled and Kv9.1 siRNA-treated neurons (Fig. 8B, left) revealed that AHPD50 was significantly shorter in the siRNA-treated group $(4.63 \pm 0.59 \mathrm{vs}$ $3.19 \pm 0.29 \mathrm{~ms}, p<0.05)$. Interestingly, AP amplitude (79.90 \pm 2.20 vs $78.01 \pm 1.90 \mathrm{mV})$, APD50 (0.84 \pm 0.07 vs $0.84 \pm 0.09 \mathrm{~ms})$, maximum rising rate $(269.50 \pm 17.97$ vs $258.16 \pm 18.80 \mathrm{mV} / \mathrm{ms})$, and AHP amplitude $(12.76 \pm 0.77$ vs $12.43 \pm 0.80 \mathrm{mV})$ did not differ between groups. 
A Recording

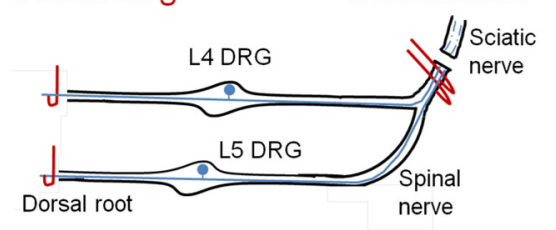

C

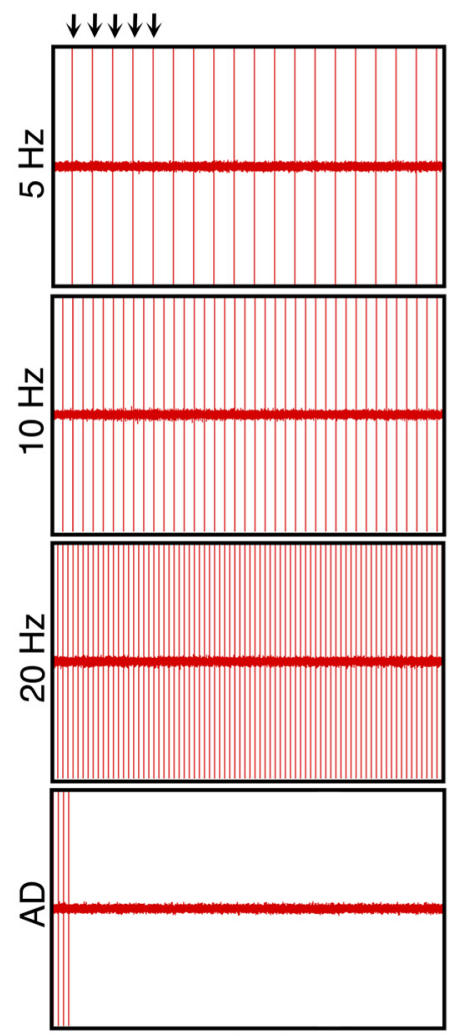

control $\downarrow \downarrow \downarrow \downarrow \downarrow$
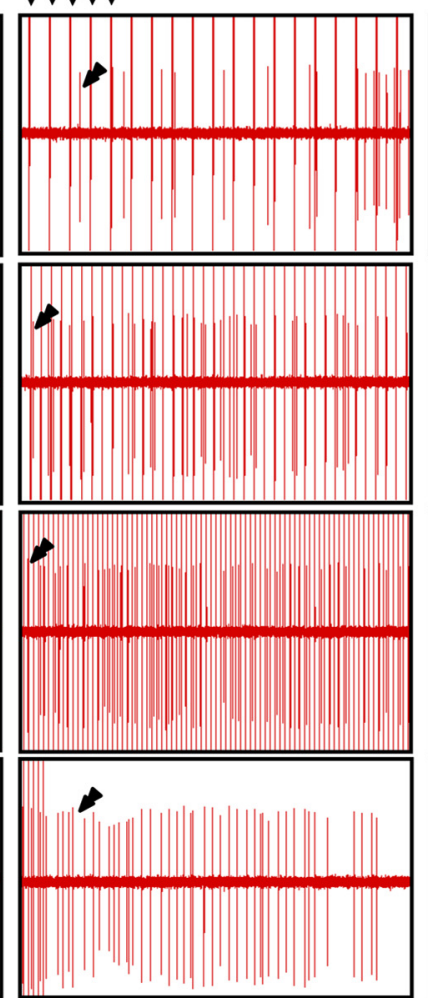

siRNA $\downarrow \downarrow \downarrow \downarrow \downarrow$
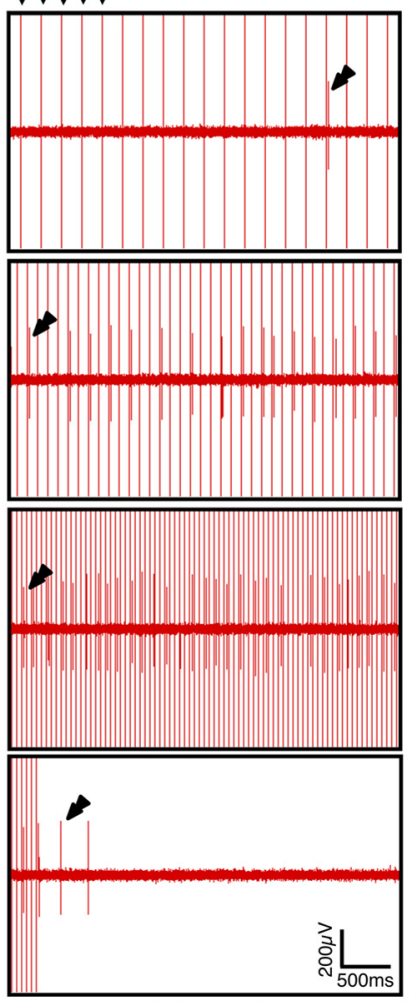

injured
SiRNA

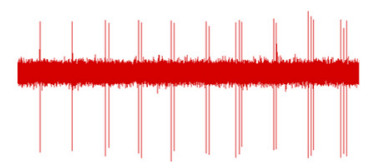

injured

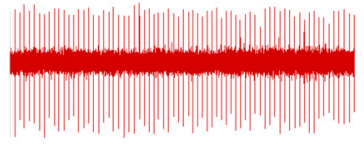

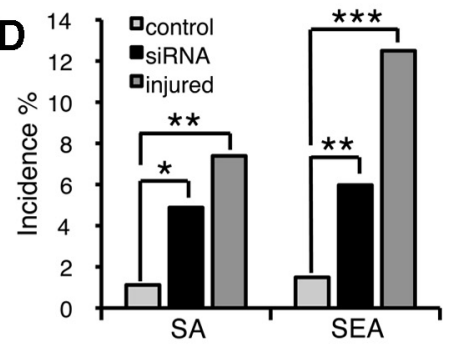

\section{$E$}

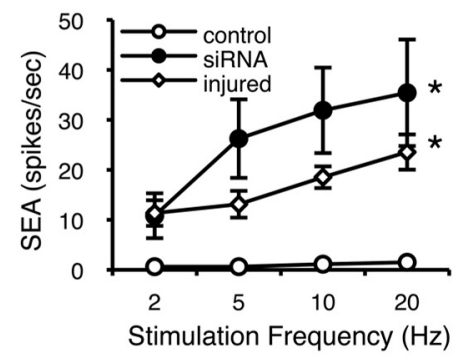

$\mathbf{F}$

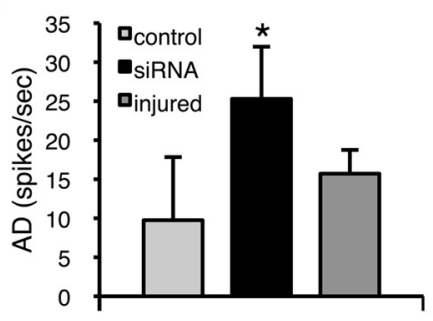

Figure 6. Kv9.1 knock-down triggers ectopic activity and a form of peripheral wind-up in response to stimulation. $\boldsymbol{A}$, Schematic illustrating the positions of stimulating and recording electrodes. $\boldsymbol{B}$, Example recordings from centrally disconnected L4/L5 strands demonstrating SA in Kv9.1 siRNA-treated or nerve-injured rats, but not in control (scrambled siRNA) animals. C, Frequencydependent SEA (denoted by double arrowheads) in Kv9.1 siRNA-treated (middle) and injured (right), but not control (left) animals. This activity is not locked in time and can be seen in between stimulation events (vertical arrows on top of $5 \mathrm{~Hz}$ stimulation traces, only first 5 shown). Also note the prolonged after-discharge (AD) observed in siRNA-treated and injured animals. $D$, Percentage of units showing SA and SEA in control $(n=269)$, Kv9.1 siRNA-treated ( $n=369)$ and injured $(n=176)$ animals $\left({ }^{*} p<0.05,{ }^{* *} p<0.01,{ }^{* * *} p<0.001\right.$ vs control, $\chi^{2}$ test). E, Firing rate of SEA units at different stimulation frequencies (mean \pm SEM; control, $n=4$; siRNA, $n=22$; injured, $n=17 ;{ }^{*} p<0.05$ vs control, two-way ANOVA with Tukey's). $\boldsymbol{F}$, Quantification of AD rate per SEA unit (mean \pm SEM; ${ }^{*} p<0.05$ vs control, Mann-Whitney test).

We then tested DRG excitability at progressively higher extracellular potassium concentrations $\left(\left[\mathrm{K}^{+}\right]_{\mathrm{e}}\right)$, low $(3 \mathrm{~mm})$ or high (6-9 $\mathrm{mm})$, to simulate the physiologically relevant $\mathrm{K}^{+}$accumulation upon elevated neuronal activity. Using this setup, we found that threshold current for AP firing was lower in injured neurons compared with naive, at both low $(1.53 \pm 0.28$ vs $2.69 \pm 0.46 \mathrm{nA}$; $p<0.05)$ and high $\left[\mathrm{K}^{+}\right]_{\mathrm{e}}(1.55 \pm 0.29$ vs $2.41 \pm 0.51 \mathrm{nA}, p<$ 0.05 , Kolmogorov-Smirnov $Z$ test; Fig. $8 C$, left), consistent with augmented excitability postinjury. When examining siRNAtreated and scrambled control-treated animals, at low $\left[\mathrm{K}^{+}\right]_{\mathrm{e}}$ the threshold current for the Kv9.1 siRNA-treated group was not different to control ( $1.91 \pm 0.23 \mathrm{vs} 1.91 \pm 0.24 \mathrm{nA})$ but, intriguingly, at high $\left[\mathrm{K}^{+}\right]_{\mathrm{e}}$ the threshold current for Kv9.1 siRNA neurons was shifted toward lower values $(1.44 \pm 0.21$ vs $1.76 \pm 0.33$ $\mathrm{nA}, p<0.05$, Kolmogorov-Smirnov $Z$ test; Fig. $8 C$, right). Another interesting feature of the nerve-injured and siRNA-treated neurons was an increased occurrence of repetitive firing to current injection in the presence of high $\left[\mathrm{K}^{+}\right]_{\mathrm{e}}$ (Fig. $8 A, B$, right). It is important to note that the observed changes in current threshold were not due to variations in input resistance or resting membrane potential, as these parameters were not significantly different between naive and injured or control and siRNAtreated animals (Table 4).

Finally, to investigate whether the Kv9.1 silencing effect is mediated through Kv2 modulation, we used the same experimental setting to measure A-fiber excitability in the presence of the Kv2 channel gating modifier stromatoxin-1, which shifts the channel activation toward more depolarized potentials (Fig. 8D). Interestingly, when we analyzed the same array of excitability parameters, the only ones altered upon application of stromatoxin-1 were threshold current (lowered from $2.87 \pm 0.38$ to $2.50 \pm 0.37 \mathrm{nA}, p<0.005, n=13$, paired $t$ test) and AHPD50 (reduced from $3.36 \pm 0.29$ to $2.76 \pm 0.30 \mathrm{~ms}, p<0.05, n=13$, paired $t$ test). All other parameters including resting membrane potential and input resistance were not altered by stromatoxin-1, and this effect was reversible upon drug washout (data not 


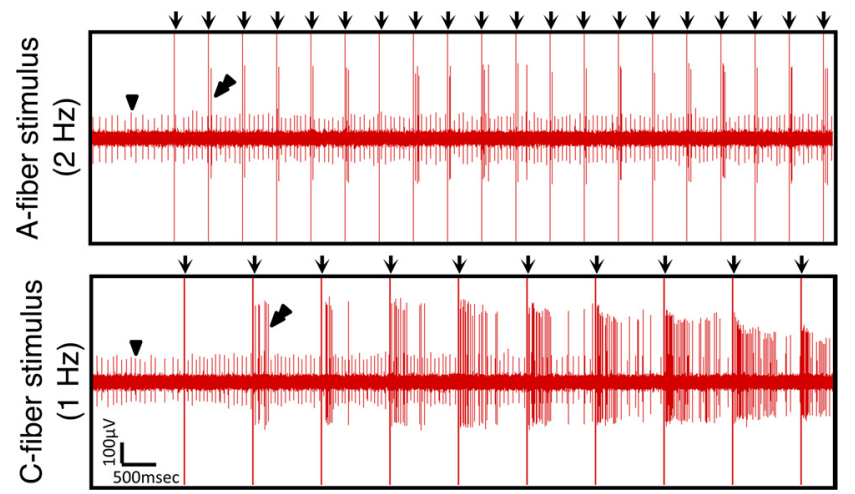

Figure 7. SEA in siRNA-treated animals is exaggerated by C-fiber activation. Recording from an siRNA-treated animal strand, featuring a small unit firing spontaneously (arrowhead). After stimulation at A-fiber strength $(2 \mathrm{~Hz})$, a second previously silent unit is recruited and shows progressive SEA (top, double arrowheads). This phenomenon was exaggerated when delivering stimuli capable of activating (-fibers, even at low frequencies $(1 \mathrm{~Hz}$, bottom).

shown), confirming the toxin-specific effect. These alterations closely mimic the ones observed by Kv9.1 inhibition through siRNA treatment, thus further highlighting a mode of action that involves Kv2 channel modulation.

In summary, our electrophysiological recordings indicate that diminished Kv9.1 function causes lower firing thresholds and augmented firing rates in A-fibers, leading to spontaneous and evoked hyperexcitability, which is dependent on extracellular potassium accumulation.

\section{Discussion}

There has been a lot of speculation about the molecular mechanism underlying peripheral hyperexcitability in chronic pain states. So far, most efforts have examined augmented sodium channel function as a cause and, despite acquiring valuable insight (Dib-Hajj et al., 2010), results indicate that postaxotomy changes cannot be satisfactorily explained by solely considering changes in sodium channel conductance (Flake et al., 2004). These and more recent findings (Emery et al., 2011) emphasize the notion that other ion channels are critical codeterminants of the injury response. In line with this view, the data presented here suggest that an important driver of increased excitability and pathological pain is downregulation of the potassium channel Kv9.1 subunit.

Development of ectopic firing following nerve lesions is one of the hallmarks of neuropathic pain, well characterized in human patients and animal pain models (Kajander and Bennett, 1992; Campero et al., 1998; Han et al., 2000). This continuous barrage of impulses provides a framework to explain spontaneous pain, and it may also feed exaggerated responses to stimulation by triggering central sensitization (Torebjörk et al., 1992; Ziegler et al., 1999). The most compelling evidence supporting a role of ectopic discharge in pain generation stems from the finding that preventing this activity from entering the spinal cord precludes the development of pain in animals (Sheen and Chung, 1993; Yoon et al., 1996; Sukhotinsky et al., 2004) and humans (Campbell et al., 1988; Gracely et al., 1992). The first interesting observation in our studies was that Kv9.1 is confined to a population of myelinated DRG neurons, which mainly give rise to $A \beta$ - and $\mathrm{A} \delta$-fibers. $\mathrm{A} \beta$-fibers are predominantly low-threshold mechanoreceptors, while $\mathrm{A} \delta$-fibers can directly mediate nociceptive responses (alongside a minority of $\mathrm{A} \beta$ nociceptors) (Djouhri and Lawson, 2004). A role for A-fiber conduction in human pain is emphasized because (1) ectopic activity has most extensively been described in A-fibers (Kajander and Bennett, 1992; Boucher et al., 2000), (2) low-threshold stimulation of A-fibers in sensitized states provokes painful sensations in humans (Campbell et al., 1988; Torebjörk et al., 1992; Ziegler et al., 1999), and (3) nerve lesions can trigger a "phenotypic switch" in A-fibers, which then start producing pain-inducing molecules (Noguchi et al., 1994; Neumann et al., 1996; Michael et al., 1999). For instance, artificial activation of injured, but not intact, myelinated fibers can trigger c-fos expression and ERK phosphorylation in spinal cord neurons, events suggestive of central sensitization (Molander et al., 1994; Wang et al., 2004).

A second intriguing result was that Kv9.1 expression is robustly attenuated within $24 \mathrm{~h}$ of axotomy, which coincides with the development of spontaneous firing and behavioral hypersensitivity in the SNT model (Liu et al., 2000). Importantly, this was a causative effect, as experimental Kv9.1 knock-down in naive animals led to elevated occurrence of spontaneous and stimulusevoked activity within A-fibers, similar in nature and magnitude to that arising after peripheral injury. The increased A-fiber excitability was also coupled to altered pain behaviors, since Kv9.1 knock-down led to a significant drop in mechanical pain thresholds of naive rats, while heat pain thresholds remained unchanged. These findings are consistent with the classical role of A-fibers in mechanotransduction, as well as with previous results demonstrating that animals treated with resiniferatoxin (a C-fiber neurotoxin) develop tactile allodynia but not thermal hyperalgesia following nerve injury (Ossipov et al., 1999).

Of particular interest, we illustrate that Kv9.1 dysfunction can also trigger a form of stimulus-dependent hyperexcitability in sensory neurons. This firing did not depend on any CNS connection as it was observed in axons that were centrally disconnected. A very similar after-discharge phenomenon induced by crossexcitation selectively in damaged A-fibers has previously been reported (Devor and Wall, 1990). Our intracellular recordings suggest that in both injured and siRNA-treated animals, this hyperexcitability is connected to lowered firing thresholds and dependent on extracellular potassium $\left(\left[\mathrm{K}^{+}\right]_{\mathrm{e}}\right)$ accumulation within the nerve following repetitive stimulation (Sykov á and Vyklicky̆, 1977; Nicoll, 1979; Svoboda et al., 1988). Thus, Kv9.1 downregulation or injury caused a shift toward lower firing thresholds when $\left[\mathrm{K}^{+}\right]_{\mathrm{e}}$ was $6 \mathrm{~mm}$ or greater (Utzschneider et al., 1992). This peripheral wind-up phenomenon is particularly suited to explain poorly understood symptoms that do not arise spontaneously and are empirically linked to A-fiber function. For instance, hyperpathia is characterized by a delayed and exaggerated painful reaction to repetitive, low-threshold stimulation and a common feature in patients is that pain is explosive and outlasts the inducing stimulus (Walters, 1959). Our data suggest that Kv9.1 ablation can render myelinated fibers prone to depolarization via a $\left[\mathrm{K}^{+}\right]_{\mathrm{e}}$-dependent pathway, which can also induce spontaneous discharge. Progressive A-fiber recruitment further elevates $\left[\mathrm{K}^{+}\right]_{\mathrm{e}}$ and initiates a chain reaction building up to a firing crescendo, which may underlie the explosive nature of the pain. Consistent with this notion, we found that SEA in A-fibers was exaggerated when stimulation strength was raised to also include C-fiber activation. Finally, the observed after-discharge could explain the after-sensation present in patients with hyperpathia. A similar cross-excitation mechanism could be involved in generation and spreading of paresthetic sensations (e.g., tingling, "pins and needles"), which can sometimes acquire unpleasant qualities (dysesthesias and pain).

Interestingly, Kv9.1 is not a pore-forming subunit and therefore its influence on sensory neuron excitability must be indirect 
Table 4. Summary of DRG intracellular recordings

\begin{tabular}{|c|c|c|c|c|c|c|c|c|c|c|}
\hline & $\begin{array}{l}l_{\text {threshold }} \text { at low } \\
{\left[\mathrm{K}^{+}\right]_{\mathrm{e}}}\end{array}$ & $\begin{array}{l}l_{\text {threshold }} \text { at high } \\
{\left[\mathrm{K}^{+}\right]_{\mathrm{e}}}\end{array}$ & $\begin{array}{l}\text { RMP at low } \\
{\left[\mathrm{K}^{+}\right]_{\mathrm{e}}}\end{array}$ & $\begin{array}{l}\text { RMP at high } \\
{\left[\mathrm{K}^{+}\right]_{\mathrm{e}}}\end{array}$ & $\begin{array}{l}\text { IR at high } \\
{\left[\mathrm{K}^{+}\right]_{\mathrm{e}}}\end{array}$ & AP amplitude & APD50 & Max rising rate & AHP amplitude & AHPD50 \\
\hline Naive & $\begin{array}{l}2.69 \pm 0.46 \\
(n=20)\end{array}$ & $\begin{array}{l}2.41 \pm 0.51 \\
(n=14)\end{array}$ & $\begin{array}{l}-64.45 \pm 1.79 \\
(n=22)\end{array}$ & $\begin{array}{l}-62.12 \pm 1.54 \\
(n=14)\end{array}$ & $\begin{array}{l}15.67 \pm 1.56 \\
(n=14)\end{array}$ & $\begin{array}{l}80.55 \pm 3.26 \\
(n=16)\end{array}$ & $\begin{array}{l}0.87 \pm 0.11 \\
(n=16)\end{array}$ & $\begin{array}{l}243.8 \pm 21.7 \\
(n=16)\end{array}$ & $\begin{array}{l}13.08 \pm 0.82 \\
(n=16)\end{array}$ & $\begin{array}{l}5.39 \pm 1.28 \\
(n=16)\end{array}$ \\
\hline Injured & $\begin{array}{l}1.53 \pm 0.28 \\
(n=19)^{*}\end{array}$ & $\begin{array}{l}1.55 \pm 0.29 \\
(n=19)^{*}\end{array}$ & $\begin{array}{l}-60.17 \pm 2.31 \\
(n=21)\end{array}$ & $\begin{array}{l}-58.74 \pm 2.04 \\
(n=19)\end{array}$ & $\begin{array}{l}15.75 \pm 3.54 \\
(n=19)\end{array}$ & $\begin{array}{l}71.09 \pm 3.04 \\
(n=21)^{*}\end{array}$ & $\begin{array}{l}1.59 \pm 0.21 \\
(n=21)^{* *}\end{array}$ & $\begin{array}{l}176.1 \pm 22.6 \\
(n=21)^{*}\end{array}$ & $\begin{array}{l}5.42 \pm 0.69 \\
(n=21)^{* *}\end{array}$ & $5.74 \pm 0.81$ \\
\hline Scrambled & $\begin{array}{l}1.91 \pm 0.24 \\
(n=26)\end{array}$ & $\begin{array}{l}1.76 \pm 0.33 \\
(n=22)\end{array}$ & $\begin{array}{l}-60.50 \pm 1.23 \\
(n=27)\end{array}$ & $\begin{array}{l}-54.09 \pm 2.10 \\
(n=22)\end{array}$ & $\begin{array}{l}13.56 \pm 1.31 \\
(n=22)\end{array}$ & $\begin{array}{l}79.97 \pm 2.20 \\
(n=30)\end{array}$ & $\begin{array}{l}0.84 \pm 0.07 \\
(n=30)\end{array}$ & $\begin{array}{l}269.5 \pm 18.0 \\
(n=30)\end{array}$ & $\begin{array}{l}12.76 \pm 0.77 \\
(n=30)\end{array}$ & $4.63 \pm 0.59$ \\
\hline siRNA & $\begin{array}{l}1.91 \pm 0.23 \\
(n=30)\end{array}$ & $\begin{array}{l}1.44 \pm 0.21 \\
(n=25)^{*}\end{array}$ & $\begin{array}{l}-62.66 \pm 1.58 \\
(n=33)\end{array}$ & $\begin{array}{l}-57.93 \pm 1.70 \\
(n=25)\end{array}$ & $\begin{array}{l}12.09 \pm 1.74 \\
(n=25)\end{array}$ & $\begin{array}{l}78.01 \pm 1.90 \\
(n=26)\end{array}$ & $\begin{array}{l}0.84 \pm 0.09 \\
(n=26)\end{array}$ & $\begin{array}{l}258.2 \pm 18.9 \\
(n=26)\end{array}$ & $\begin{array}{l}12.43 \pm 0.80 \\
(n=26)\end{array}$ & $3.19 \pm 0.29$ \\
\hline
\end{tabular}

$I_{\text {threshold }}$ threshold current, in $\mathrm{nA}$; RMP, resting membrane potential, in $\mathrm{mV} ; \mathrm{IR}$, input resistance, in $\mathrm{M} \Omega$; AP amplitude, in $\mathrm{mV}$; APD50, AP half-width, in ms; maximal rising rate, in V/s; AHP, afterhyperpolarization; AHP amplitude, in $\mathrm{mV}$; AHPD50, AHP half-width, in ms.

A
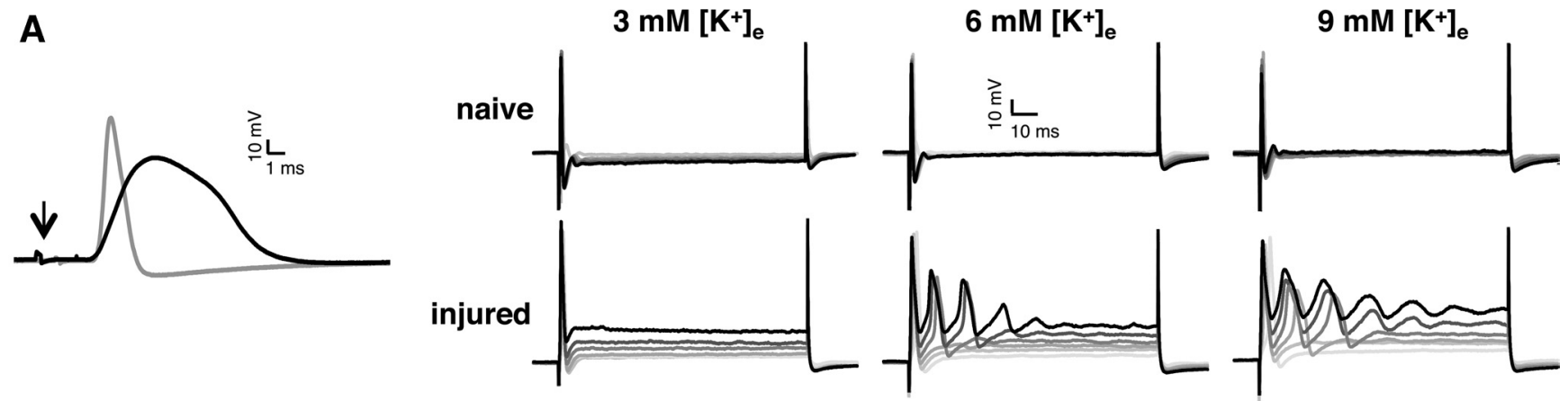

B
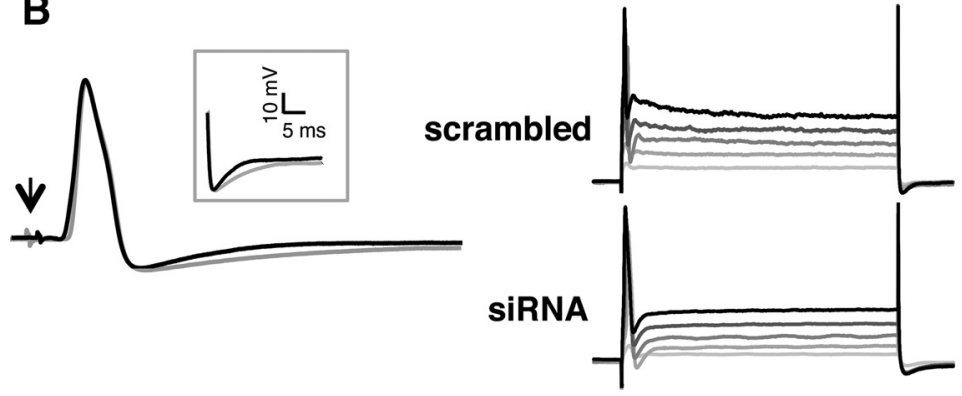

部
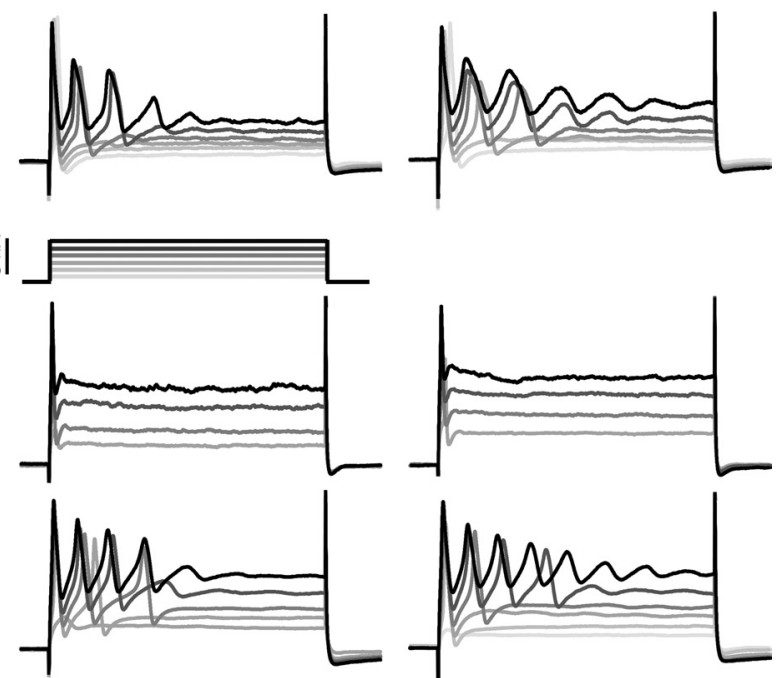

D
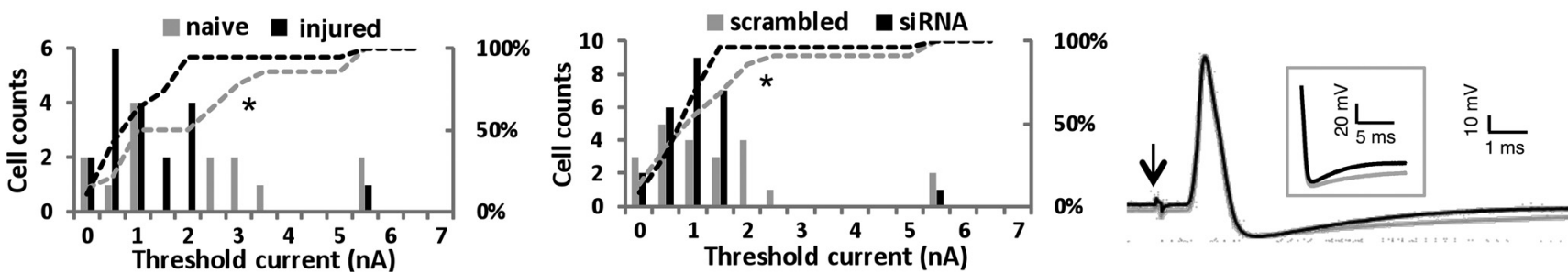

Figure 8. Intracellular APs from naive, injured (3-5 d postaxotomy), scrambled siRNA-treated, and Kv9.1 siRNA-treated neurons and the effect of elevated $\left[K^{+}\right]_{e}$ on excitability. $\boldsymbol{A}_{\text {, Left, }}$ Representative APs evoked by dorsal root stimulation from a naive (gray) or an injured (black) cell. Arrow indicates the stimulus artifact. Right, Responses to a series of depolarizing current injections from a naive and an injured neuron at 3,6, and $9 \mathrm{~mm}\left[\mathrm{~K}^{+}\right]_{e}$. B, Left, Representative APs from scrambled- and Kv9.1 siRNA-treated neurons. The inset highlights the shortened AHP in Kv9.1 siRNA-treated neuron on a different scale. Right, neuronal responses to a series of depolarizing current injections from control or Kv9.1 siRNA-treated neurons at 3,6 , and $9 \mathrm{~mm}\left[\mathrm{~K}^{+}\right]_{\mathrm{e}} \cdot \mathrm{C}, \mathrm{Comparison}$ of frequency distribution of threshold current at elevated $\left[\mathrm{K}^{+}\right]_{\mathrm{e}}(6-9 \mathrm{~mm})$ between naive/injured neurons (left) and scrambled/Kv9.1 siRNA-treated neurons (right). Dashed lines indicate the respective cumulative percentages, illustrating the shift toward lower values in injured and Kv9.1 siRNA-treated neurons. $\boldsymbol{D}$, representative AP from a naive neuron in the absence (black) or presence (gray) of the Kv2 blocker stromatoxin-1 (ScTx). The inset highlights the shortened AHP caused by ScTx, similar to Kv9.1 siRNA treatment.

(Salinas et al., 1997). Kv9.1 can form heterotetramers with members of the Kv2 family (Kv2.1 and Kv2.2) in vitro (Kerschensteiner et al., 2005) and this interaction leads to alteration of the functional channel kinetics (Salinas et al., 1997; Stocker and Kerschensteiner, 1998; Kerschensteiner et al., 2005), such as modifications in current amplitude and voltage-dependency of activation and inactivation. Interestingly, Kv9.1 modulation could have opposing actions depending on the ion channel complement of the cell; computer simulations predict that the presence of Kv9.1 can, in certain contexts, produce an inhibition of firing during sustained depolarization (Richardson and Kaczmarek, 2000). Our study is the first one to address the effect of Kv9.1 in vivo and our results strongly suggest that, in sensory neurons, Kv9.1 is an inhibitor of neuronal excitability. Although 
an entirely novel interaction cannot be excluded, the ScTx experiment indicates that the Kv9.1 effect on excitability is indeed mediated via modulation of Kv2 function, since Kv2 blockade induced very similar electrophysiological changes. Importantly, the shortened hyperpolarization (reduced AHPD50) observed in both ScTx and Kv9.1 siRNA-treated cells could explain the increase in firing frequency observed during elevated $\left[\mathrm{K}^{+}\right]_{\mathrm{e}}$. Inhibition of Kv9.1 or Kv2 also resulted in lowered firing thresholds, presumably through a reduction in Kv2 channel conductance, but more work will be needed to decipher the exact molecular mechanism of this alteration.

Another possibility is that Kv9.1 association with Kv2 members in vivo affects channel trafficking (Pongs and Schwarz, 2010); a Kv9.1-contained signal could promote Kv2 incorporation to cell membrane or transport to the axon hillock, effectively increasing Kv2 function. For instance, it was recently demonstrated that phosphorylation-dependent association of Kv1 with the auxiliary subunit $\mathrm{Kv} \beta 2$ regulates targeting to the axon hillock (Vacher et al., 2011). Interestingly, Kv2.1 clustering and function in CNS neurons is also phosphorylation dependent and Kv9.1 can donate a number of phosphorylation sites upon association (Salinas et al., 1997; Stocker and Kerschensteiner, 1998; Cerda and Trimmer, 2011).

In many neurons, Kv2.1 conductance represents the majority of delayed rectifier current (Murakoshi and Trimmer, 1999) and Kv2.1 modulation has a very prominent role in dynamic control of excitability (Misonou et al., 2004). We have shown here that myelinated DRG neurons have the capacity for Kv2 and Kv9.1 interaction, since they largely coexpress these subunits. A similar Kv2 modulation by silent subunits is present in small DRG neurons, where two distinct Kv2.1 current components are detected: one reflecting homotetrameric Kv2.1 channels and the other attributed to heterotetramers of Kv2.1 with modulatory subunits (Bocksteins et al., 2009). Here, we conclude that the Kv9.1 subunit that is dramatically downregulated following peripheral nerve injury confers plasticity of Kv2 channel conductance, which in turn regulates the intrinsic excitability of myelinated primary sensory neurons. Similarly, different combinations of Kv4.3 with Kv1.4 and Kv3.4 are linked to A-current plasticity in sensory neurons, and axotomy-induced Kv4.3 downregulation in small DRG neurons has particular relevance to evoked neuropathic pain (Chien et al., 2007). Interestingly, Kv2.1 protein has also been reported slightly reduced $(\sim 20 \%)$ in large neurons after axotomy (Ishikawa et al., 1999) and therefore we cannot exclude at least some involvement of Kv2.1 downregulation in the hyperexcitable phenotype following injury.

The identification of numerous human channelopathies leading to detrimental nervous system dysfunctions, many of which are coupled to hyperexcitability and pain, highlights the importance of ion channels for physiological function (Cregg et al., 2010). Our results propose that Kv9.1 downregulation after nerve injury may be the molecular switch controlling myelinated sensory neuron hyperexcitability. Intriguingly, a recent widegenome association screen in humans identified a Kv9.1 polymorphism associated with susceptibility to develop chronic neuropathic pain after back surgery or leg amputation (Costigan et al., 2010), suggesting that the mechanisms described in our studies will be of direct clinical relevance to human pain. Future efforts to elucidate the precise pathways involved, combined with approaches aiming to compensate loss of Kv9.1 function, may create novel therapeutic opportunities for neuropathic pain management.

\section{References}

Abdulla FA, Smith PA (2001) Axotomy- and autotomy-induced changes in $\mathrm{Ca}^{2+}$ and $\mathrm{K}+$ channel currents of rat dorsal root ganglion neurons. J Neurophysiol 85:644-658. Medline

Amir R, Argoff CE, Bennett GJ, Cummins TR, Durieux ME, Gerner P, Gold MS, Porreca F, Strichartz GR (2006) The role of sodium channels in chronic inflammatory and neuropathic pain. J Pain 7:S1-S29. CrossRef Medline

Baron R (2009) Neuropathic pain: a clinical perspective. Handb Exp Pharmacol 194:3-30.

Bennett GJ, Chung JM, Honore M, Seltzer Z (2003) Models of neuropathic pain in the rat. Curr Protoc Neurosci Chapter 9:Unit 9.14. Medline

Bocksteins E, Raes AL, Van de Vijver G, Bruyns T, Van Bogaert PP, Snyders DJ (2009) Kv2.1 and silent Kv subunits underlie the delayed rectifier K+ current in cultured small mouse DRG neurons. Am J Physiol Cell Physiol 296:C1271-1278. CrossRef Medline

Boucher TJ, Okuse K, Bennett DL, Munson JB, Wood JN, McMahon SB (2000) Potent analgesic effects of GDNF in neuropathic pain states. Science 290:124-127. CrossRef Medline

Calvo M, Zhu N, Tsantoulas C, Ma Z, Grist J, Loeb JA, Bennett DL (2010) Neuregulin-ErbB signaling promotes microglial proliferation and chemotaxis contributing to microgliosis and pain after peripheral nerve injury. J Neurosci 30:5437-5450. CrossRef Medline

Campbell JN, Raja SN, Meyer RA, Mackinnon SE (1988) Myelinated afferents signal the hyperalgesia associated with nerve injury. Pain 32:89-94. CrossRef Medline

Campero M, Serra J, Marchettini P, Ochoa JL (1998) Ectopic impulse generation and autoexcitation in single myelinated afferent fibers in patients with peripheral neuropathy and positive sensory symptoms. Muscle Nerve 21:1661-1667. CrossRef Medline

Cerda O, Trimmer JS (2011) Activity-dependent phosphorylation of neuronal Kv2.1 potassium channels by CDK5. J Biol Chem 286:28738-28748. CrossRef Medline

Chien LY, Cheng JK, Chu D, Cheng CF, Tsaur ML (2007) Reduced expression of A-type potassium channels in primary sensory neurons induces mechanical hypersensitivity. J Neurosci 27:9855-9865. CrossRef Medline

Costigan M, et al. (2010) Multiple chronic pain states are associated with a common amino acid-changing allele in KCNS1. Brain 133:2519-2527. CrossRef Medline

Cox JJ, Reimann F, Nicholas AK, Thornton G, Roberts E, Springell K, Karbani G, Jafri H, Mannan J, Raashid Y, Al-Gazali L, Hamamy H, Valente EM, Gorman S, Williams R, McHale DP, Wood JN, Gribble FM, Woods CG (2006) An SCN9A channelopathy causes congenital inability to experience pain. Nature 444:894-898. CrossRef Medline

Cregg R, Momin A, Rugiero F, Wood JN, Zhao J (2010) Pain channelopathies. J Physiol 588:1897-1904. CrossRef Medline

Devor M, Wall PD (1990) Cross-excitation in dorsal root ganglia of nerveinjured and intact rats. J Neurophysiol 64:1733-1746. Medline

Dib-Hajj SD, Cummins TR, Black JA, Waxman SG (2010) Sodium channels in normal and pathological pain. Annu Rev Neurosci 33:325-347. CrossRef Medline

Djouhri L, Lawson SN (2004) Abeta-fiber nociceptive primary afferent neurons: a review of incidence and properties in relation to other afferent A-fiber neurons in mammals. Brain Res Brain Res Rev 46:131-145. Medline

Dussor GO, Price TJ, Flores CM (2003) Activating transcription factor 3 mRNA is upregulated in primary cultures of trigeminal ganglion neurons. Brain Res Mol Brain Res 118:156-159. Medline

Emery EC, Young GT, Berrocoso EM, Chen L, McNaughton PA (2011) $\mathrm{HCN} 2$ ion channels play a central role in inflammatory and neuropathic pain. Science 333:1462-1466. CrossRef Medline

Fantozzi I, Platoshyn O, Wong AH, Zhang S, Remillard CV, Furtado MR, Petrauskene OV, Yuan JX (2006) Bone morphogenetic protein-2 upregulates expression and function of voltage-gated $\mathrm{K}+$ channels in human pulmonary artery smooth muscle cells. Am J Physiol Lung Cell Mol Physiol 291:L993-1004. CrossRef Medline

Flake NM, Lancaster E, Weinreich D, Gold MS (2004) Absence of an association between axotomy-induced changes in sodium currents and excitability in DRG neurons from the adult rat. Pain 109:471-480. CrossRef Medline

Fricker FR, Zhu N, Tsantoulas C, Abrahamsen B, Nassar MA, Thakur M, Garratt AN, Birchmeier C, McMahon SB, Wood JN, Bennett DL (2009) 
Sensory axon-derived neuregulin-1 is required for axoglial signaling and normal sensory function but not for long-term axon maintenance. J Neurosci 29:7667-7678. CrossRef Medline

Gracely RH, Lynch SA, Bennett GJ (1992) Painful neuropathy: altered central processing maintained dynamically by peripheral input. Pain 51:175194. CrossRef Medline

Haanpää M, Attal N, Backonja M, Baron R, Bennett M, Bouhassira D, Cruccu G, Hansson P, Haythornthwaite JA, Iannetti GD, Jensen TS, Kauppila T, Nurmikko TJ, Rice AS, Rowbotham M, Serra J, Sommer C, Smith BH, Treede RD (2011) NeuPSIG guidelines on neuropathic pain assessment. Pain 152:14-27. CrossRef Medline

Han HC, Lee DH, Chung JM (2000) Characteristics of ectopic discharges in a rat neuropathic pain model. Pain 84:253-261. CrossRef Medline

Ishikawa K, Tanaka M, Black JA, Waxman SG (1999) Changes in expression of voltage-gated potassium channels in dorsal root ganglion neurons following axotomy. Muscle Nerve 22:502-507. CrossRef Medline

Kajander KC, Bennett GJ (1992) Onset of a painful peripheral neuropathy in rat: a partial and differential deafferentation and spontaneous discharge in A beta and A delta primary afferent neurons. J Neurophysiol 68:734-744. Medline

Kerschensteiner D, Soto F, Stocker M (2005) Fluorescence measurements reveal stoichiometry of $\mathrm{K}+$ channels formed by modulatory and delayed rectifier alpha-subunits. Proc Natl Acad Sci U S A 102:6160-6165. CrossRef Medline

Khasar SG, Gold MS, Levine JD (1998) A tetrodotoxin-resistant sodium current mediates inflammatory pain in the rat. Neurosci Lett 256:17-20. CrossRef Medline

Knock GA, Snetkov VA, Shaifta Y, Drndarski S, Ward JP, Aaronson PI (2008a) Role of src-family kinases in hypoxic vasoconstriction of rat pulmonary artery. Cardiovasc Res 80:453-462. CrossRef Medline

Knock GA, Shaifta Y, Snetkov VA, Vowles B, Drndarski S, Ward JP, Aaronson PI (2008b) Interaction between src family kinases and rho-kinase in agonist-induced $\mathrm{Ca} 2+$-sensitization of rat pulmonary artery. Cardiovasc Res 77:570-579. Medline

LaCroix-Fralish ML, Austin JS, Zheng FY, Levitin DJ, Mogil JS (2011) Patterns of pain: meta-analysis of microarray studies of pain. Pain 152:18881898. CrossRef Medline

Liu CN, Wall PD, Ben-Dor E, Michaelis M, Amir R, Devor M (2000) Tactile allodynia in the absence of $\mathrm{C}$-fiber activation: altered firing properties of DRG neurons following spinal nerve injury. Pain 85:503-521. CrossRef Medline

Luo MC, Zhang DQ, Ma SW, Huang YY, Shuster SJ, Porreca F, Lai J (2005) An efficient intrathecal delivery of small interfering RNA to the spinal cord and peripheral neurons. Mol Pain 1:29. CrossRef Medline

Ma C, Shu Y, Zheng Z, Chen Y, Yao H, Greenquist KW, White FA, LaMotte RH (2003) Similar electrophysiological changes in axotomized and neighboring intact dorsal root ganglion neurons. J Neurophysiol 89: 1588-1602. Medline

Maratou K, Wallace VC, Hasnie FS, Okuse K, Hosseini R, Jina N, Blackbeard J, Pheby T, Orengo C, Dickenson AH, McMahon SB, Rice AS (2009) Comparison of dorsal root ganglion gene expression in rat models of traumatic and HIV-associated neuropathic pain. Eur J Pain 13:387-398. CrossRef Medline

Marchand F, Tsantoulas C, Singh D, Grist J, Clark AK, Bradbury EJ, McMahon SB (2009) Effects of Etanercept and Minocycline in a rat model of spinal cord injury. Eur J Pain 13:673-681. CrossRef Medline

Michael GJ, Averill S, Nitkunan A, Rattray M, Bennett DL, Yan Q, Priestley JV (1997) Nerve growth factor treatment increases brain-derived neurotrophic factor selectively in TrkA-expressing dorsal root ganglion cells and in their central terminations within the spinal cord. J Neurosci 17: 8476-8490. Medline

Michael GJ, Averill S, Shortland PJ, Yan Q, Priestley JV (1999) Axotomy results in major changes in BDNF expression by dorsal root ganglion cells: $\mathrm{BDNF}$ expression in large trkB and trkC cells, in pericellular baskets, and in projections to deep dorsal horn and dorsal column nuclei. Eur J Neurosci 11:3539-3551. CrossRef Medline

Michaelis M, Liu X, Jänig W (2000) Axotomized and intact muscle afferents but no skin afferents develop ongoing discharges of dorsal root ganglion origin after peripheral nerve lesion. J Neurosci 20:2742-2748. Medline

Misonou H, Mohapatra DP, Park EW, Leung V, Zhen D, Misonou K, Anderson AE, Trimmer JS (2004) Regulation of ion channel localization and phosphorylation by neuronal activity. Nat Neurosci 7:711-718. CrossRef Medline

Molander C, Hongpaisan J, Persson JK (1994) Distribution of c-fos expressing dorsal horn neurons after electrical stimulation of low threshold sensory fibers in the chronically injured sciatic nerve. Brain Res 644:74-82. CrossRef Medline

Murakoshi H, Trimmer JS (1999) Identification of the Kv2.1 K+ channel as a major component of the delayed rectifier $\mathrm{K}+$ current in rat hippocampal neurons. J Neurosci 19:1728-1735. Medline

Nassar MA, Levato A, Stirling LC, Wood JN (2005) Neuropathic pain develops normally in mice lacking both $\mathrm{Na}(\mathrm{v}) 1.7$ and $\mathrm{Na}(\mathrm{v}) 1.8$. Mol Pain 1:24. CrossRef Medline

Nassar MA, Baker MD, Levato A, Ingram R, Mallucci G, McMahon SB, Wood JN (2006) Nerve injury induces robust allodynia and ectopic discharges in Nav1.3 null mutant mice. Mol Pain 2:33. CrossRef Medline

Neumann S, Doubell TP, Leslie T, Woolf CJ (1996) Inflammatory pain hypersensitivity mediated by phenotypic switch in myelinated primary sensory neurons. Nature 384:360-364. CrossRef Medline

Nicoll RA (1979) Dorsal root potentials and changes in extracellular potassium in the spinal cord of the frog. J Physiol 290:113-127. Medline

Noguchi K, Dubner R, De Leon M, Senba E, Ruda MA (1994) Axotomy induces preprotachykinin gene expression in a subpopulation of dorsal root ganglion neurons. J Neurosci Res 37:596-603. CrossRef Medline

O'Connor AB, Dworkin RH (2009) Treatment of neuropathic pain: an overview of recent guidelines. Am J Med 122:S22-S32. CrossRef Medline

Ossipov MH, Bian D, Malan TP Jr, Lai J, Porreca F (1999) Lack of involvement of capsaicin-sensitive primary afferents in nerve-ligation injury induced tactile allodynia in rats. Pain 79:127-133. CrossRef Medline

Pongs O, Schwarz JR (2010) Ancillary subunits associated with voltagedependent K+ channels. Physiol Rev 90:755-796. CrossRef Medline

Richardson FC, Kaczmarek LK (2000) Modification of delayed rectifier potassium currents by the Kv9.1 potassium channel subunit. Hear Res 147: 21-30. CrossRef Medline

Salinas M, Duprat F, Heurteaux C, Hugnot JP, Lazdunski M (1997) New modulatory alpha subunits for mammalian Shab $\mathrm{K}+$ channels. J Biol Chem 272:24371-24379. CrossRef Medline

Sapunar D, Ljubkovic M, Lirk P, McCallum JB, Hogan QH (2005) Distinct membrane effects of spinal nerve ligation on injured and adjacent dorsal root ganglion neurons in rats. Anesthesiology 103:360-376. CrossRef Medline

Sheen K, Chung JM (1993) Signs of neuropathic pain depend on signals from injured nerve fibers in a rat model. Brain Res 610:62-68. CrossRef Medline

Shortland PJ, Baytug B, Krzyzanowska A, McMahon SB, Priestley JV, Averill S (2006) ATF3 expression in L4 dorsal root ganglion neurons after L5 spinal nerve transection. Eur J Neurosci 23:365-373. CrossRef Medline

Stocker M, Kerschensteiner D (1998) Cloning and tissue distribution of two new potassium channel alpha-subunits from rat brain. Biochem Biophys Res Commun 248:927-934. CrossRef Medline

Sukhotinsky I, Ben-Dor E, Raber P, Devor M (2004) Key role of the dorsal root ganglion in neuropathic tactile hypersensibility. Eur J Pain 8:135143. CrossRef Medline

Svoboda J, Motin V, Hájek I, Sykov á E (1988) Increase in extracellular potassium level in rat spinal dorsal horn induced by noxious stimulation and peripheral injury. Brain Res 458:97-105. CrossRef Medline

Syková E, Vyklicky̆ L (1977) Changes of extracellular potassium activity in isolated spinal cord of frog under high $\mathrm{Mg}(2+)$ concentration. Neurosci Lett 4:161-165. CrossRef Medline

Torebjörk HE, Lundberg LE, LaMotte RH (1992) Central changes in processing of mechanoreceptive input in capsaicin-induced secondary hyperalgesia in humans. J Physiol 448:765-780. Medline

Utzschneider D, Kocsis J, Devor M (1992) Mutual excitation among dorsal root ganglion neurons in the rat. Neurosci Lett 146:53-56. CrossRef Medline

Vacher H, Yang JW, Cerda O, Autillo-Touati A, Dargent B, Trimmer JS (2011) Cdk-mediated phosphorylation of the Kvbeta2 auxiliary subunit regulates Kv1 channel axonal targeting. J Cell Biol 192:813-824. CrossRef Medline

Walters A (1959) The differentiation of causalgia and hyperpathia. Can Med Assoc J 80:105-109. Medline

Wang H, Dai Y, Fukuoka T, Yamanaka H, Obata K, Tokunaga A, Noguchi K (2004) Enhancement of stimulation-induced ERK activation in the spi- 
nal dorsal horn and gracile nucleus neurons in rats with peripheral nerve injury. Eur J Neurosci 19:884-890. CrossRef Medline

Wong LF, Yip PK, Battaglia A, Grist J, Corcoran J, Maden M, Azzouz M, Kingsman SM, Kingsman AJ, Mazarakis ND, McMahon SB (2006) Retinoic acid receptor beta2 promotes functional regeneration of sensory axons in the spinal cord. Nat Neurosci 9:243-250. CrossRef Medline
Yoon YW, Na HS, Chung JM (1996) Contributions of injured and intact afferents to neuropathic pain in an experimental rat model. Pain 64:2736. CrossRef Medline

Ziegler EA, Magerl W, Meyer RA, Treede RD (1999) Secondary hyperalgesia to punctate mechanical stimuli. Central sensitization to A-fibre nociceptor input. Brain 122:2245-2257. CrossRef Medline 